\title{
The Arabidopsis pop2-1 mutant reveals the involvement of GABA transaminase in salt stress tolerance
}

Hugues Renault ${ }^{1,2}$, Valérie Roussel ${ }^{1,3}$, Abdelhak El Amrani $^{2}$, Matthieu Arzel $^{1}$, David Renault ${ }^{2}$, Alain Bouchereau ${ }^{1}$, Carole Deleu $^{1 *}$

\begin{abstract}
Background: GABA ( $\gamma$-aminobutyric acid) is a non protein amino acid that has been reported to accumulate in a number of plant species when subjected to high salinity and many other environmental constraints. However, no experimental data are to date available on the molecular function of GABA and the involvement of its metabolism in salt stress tolerance in higher plants. Here, we investigated the regulation of GABA metabolism in Arabidopsis thaliana at the metabolite, enzymatic activity and gene transcription levels upon $\mathrm{NaCl}$ stress.
\end{abstract}

Results: We identified the GABA transaminase (GABA-T), the first step of GABA catabolism, as the most responsive to $\mathrm{NaCl}$. We further performed a functional analysis of the corresponding gene POP2 and demonstrated that the previously isolated loss-of-function pop2-1 mutant was oversensitive to ionic stress but not to osmotic stress suggesting a specific role in salt tolerance. $\mathrm{NaCl}$ oversensitivity was not associated with overaccumulation of $\mathrm{Na}^{+}$ and $\mathrm{Cl}^{-}$but mutant showed a slight decrease in $\mathrm{K}^{+}$. To bring insights into POP2 function, a promoter-reporter gene strategy was used and showed that POP2 was mainly expressed in roots under control conditions and was induced in primary root apex and aerial parts of plants in response to NaCl. Additionally, GC-MS- and UPLC-based metabolite profiling revealed major changes in roots of pop2-1 mutant upon $\mathrm{NaCl}$ stress including accumulation of amino acids and decrease in carbohydrates content.

Conclusions: GABA metabolism was overall up-regulated in response to $\mathrm{NaCl}$ in Arabidopsis. Particularly, GABA-T was found to play a pivotal function and impairment of this step was responsible for a decrease in salt tolerance indicating that GABA catabolism was a determinant of Arabidopsis salt tolerance. GABA-T would act in salt responses in linking $\mathrm{N}$ and $\mathrm{C}$ metabolisms in roots.

\section{Background}

Salt stress affects crop productivity worldwide, especially in irrigated lands [1], and can thus lead to dramatic consequences in food availability. Hence, determinants of plant salt tolerance are intensively investigated to identify targets for plant breeding and to create salt tolerant varieties. Three cellular components of salt tolerance have been proposed in plants: $(i)$ osmotic stress tolerance, $(i i) \mathrm{Na}^{+}$exclusion capacity and (iii) tissue tolerance to $\mathrm{Na}^{+}$accumulation [2]. Unlike halophytic species, the glycophytic plant-model Arabidopsis thaliana is

\footnotetext{
* Correspondence: carole.deleu@univ-rennes1.fr

'INRA - Agrocampus Ouest - Université de Rennes 1, UMR 118 Amélioration des Plantes et Biotechnologies Végétales, F-35653, Le Rheu cedex, France
}

sensitive to moderate levels of $\mathrm{NaCl}$. This has raised the question of its relevance in salt tolerance studies [3]. However, thanks to genetic and molecular tools developed around this species, several genes involved in plant salt tolerance have been highlighted. Thus, many mutants or transgenic lines of $A$. thaliana were shown to display differential levels of $\mathrm{NaCl}$ tolerance and this mostly concerned genes involved in ion transport [4-8], detoxication processes $[9,10]$ or metabolite biosynthesis $[11,12]$.

Among stress-responsive metabolites, $\gamma$-aminobutyric acid is of special interest since the molecule accumulates in response to a wide range of environmental stimuli [13] although its function in plants is still a matter of debate $[14,15]$. GABA is a widespread non protein 
amino acid, from prokaryotes to eukaryotes. It has been first discovered in plants in the middle of the $20^{\text {th }}$ century [16] but rapidly attention shifted to its signaling function in mammals central nervous system as a neurotransmitter. In plants, speculative functions have been attributed to GABA metabolism such as osmoregulation [17] and glutamate homeostasis control [18]. Moreover, it has been demonstrated to participate to $\mathrm{pH}$ regulation $[19,20]$ and bypass of TCA cycle [21]. GABA has also been shown to act as a signaling molecule in plants as reported for nitrate uptake modulation [22], 14-3-3 genes regulation [23] and pollen tube growth and guidance [24].

In plants and animals, GABA metabolism is sum up in a three-enzyme-pathway that takes place in two cellular compartments (figure 1). GABA is mainly synthesized from L-glutamate owing to the activity of the cytosolic glutamate decarboxylase (GAD, EC 4.1.1.15). GABA is then transported into the mitochondrion to be catabolized by the GABA transaminase (GABA-T, EC 2.6.1.19) which converts GABA to succinic semialdehyde (SSA) [25]. Subsequently, SSA is oxidized by the mitochondrial succinic semialdehyde dehydrogenase (SSADH, EC 1.2.1.16) to produce succinate [26]. Alternatively, SSA can also be reduced in the cytosol via the activity of the $\gamma$-hydroxybutyrate dehydrogenase (GHBDH, EC 1.1.1.61) that produces $\gamma$-hydroxybutyrate (GHB) [27].

Most of attention has been focused on GABA synthesis under environmental stress owing to changes of catalytic properties of plants GAD depending on cytosolic $\mathrm{pH}$ and activity of $\mathrm{Ca}^{2+} /$ calmodulin complex $[28,29]$, two known stress-modulated factors [17]. On this basis, it has been hypothesized that GABA level could be mainly controlled by the rate of its synthesis. However, isolation and characterization of Arabidopsis GABA-T deficient mutants demonstrated that GABA levels could also result from the rate of its degradation [24,30,31].
Arabidopsis genome contains only one GABA-T encoding gene (At3 g22200; figure 1) [25], subsequently termed POP2 (Pollen-Pistil Incompatibility 2) [24], whereas 5 genes putatively encode GAD (GAD1-5; figure 1) [32]. POP2 uses pyruvate as GABA amino group acceptor (GABA-TP activity) [25], while in mammals GABA-T exclusively uses 2-ketoglutarate as amino group acceptor (GABA-TK activity) [33]. Recently, it has been shown that POP2 can also uses glyoxylate as amino acceptor and thus produces glycine [34]. POP2 gene product is a $55.2 \mathrm{kDa}$ polypeptide with a pyridoxal-5-phosphate binding domain and a mitochondrial peptide signal [34], and shares little homology with nonplant GABA-T genes [25]. In A.thaliana, POP2 gene was linked to responsiveness to volatile $E$-2-hexenal [30], alanine accumulation occurring in roots during hypoxia [35] and growth and guidance of pollen tubes [24].

In this study, we investigated the regulation of GABA metabolism upon $\mathrm{NaCl}$ treatments in A. thaliana at the metabolite, enzymatic activity and gene transcription levels. We identified the GABA-T step as a key point of regulation of GABA metabolism and further performed a functional analysis of the POP2 gene that encodes GABA-T.

\section{Results}

GABA-T is the most responsive step of GABA metabolism upon $\mathrm{NaCl}$ stress in $A$. thaliana

No data specifically devoted to description of GABA level changes under $\mathrm{NaCl}$ stress conditions are to date available in $A$. thaliana. Hence, we followed the kinetics of GABA level changes and its organ partitioning in wild-type plantlets (WT) subjected to $150 \mathrm{mM} \mathrm{NaCl}$ treatment. Figure $2 \mathrm{~A}$ shows that GABA readily accumulated during $\mathrm{NaCl}$ treatment in A. thaliana at the whole-plant level. After 4 days of treatment, GABA content reached 3.8-fold higher level in $\mathrm{NaCl}$-treated

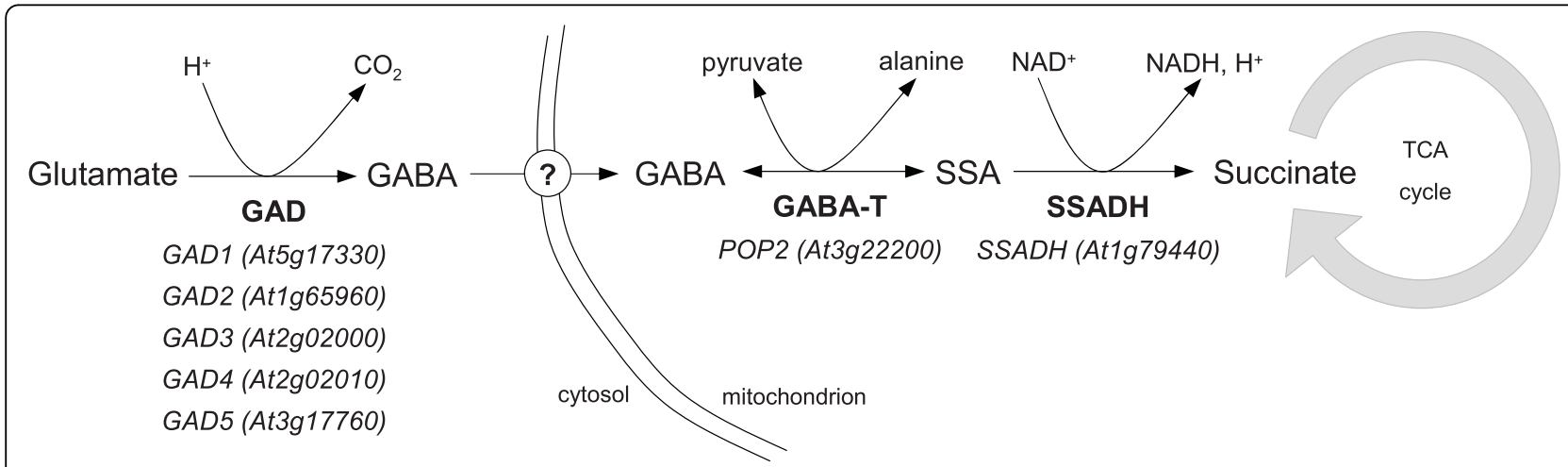

Figure 1 Schematic representation of the GABA metabolic pathway in Arabidopsis thaliana. GAD, glutamate decarboxylase; GABA-T, GABA transaminase; SSA, succinic semialdehyde; SSADH, succinic semialdehyde dehydrogenase. For each enzyme, the corresponding genes loci are shown. 
plantlets than in control ones (7.1 vs $1.9 \mu$ moles. $\mathrm{g}^{-1} \mathrm{DW}$; figure 2A). Under control conditions, GABA was shown to be much more abundant in root tissues than in shoot tissues ( 7.5 vs $0.7 \mu$ moles. ${ }^{-1} \mathrm{DW}$; figure $2 \mathrm{~B}$ ) whereas, after 4 days of treatment with $\mathrm{NaCl}$, shoot and root tissues exhibited about equal amount of GABA (9.9 vs $10.9 \mu$ moles. $\left.\mathrm{g}^{-1} \mathrm{DW}\right)$. Shoots of $\mathrm{NaCl}$-treated plantlets were actually shown to accumulate 14-fold more GABA than control ones while roots accumulated only 1.5 -fold more GABA (figure 2B).

GAD and GABA-TP catalytic activities were determined in vitro in WT plantlets subjected to $\mathrm{NaCl}$ treatments to decipher biochemical determinants of GABA accumulation. GAD activity showed surprising variations (figure 2C) in response to $\mathrm{NaCl}$ treatment. It was thus found to be significantly decreased in plantlets treated for $24 \mathrm{~h}$ with $150 \mathrm{mM} \mathrm{NaCl}$ while, after 4 days of treatment, it reached 1.5-fold higher level than in control plantlets (49.7 vs 33.9 nmoles. $\mathrm{min}^{-1} . \mathrm{mg}^{-1}$ protein; figure 2C). GAD activity was not shown to be significantly different in plantlets treated for 4 days with $50 \mathrm{mM}$ and $100 \mathrm{mM} \mathrm{NaCl}$ (figure 2D). Figure 2E shows that GABA$\mathrm{TP}$ activity increased rapidly in response to treatment with $150 \mathrm{mM} \mathrm{NaCl}$. In plantlets treated for 4 days, GABA-TP activity was 2.1-fold higher than in control plantlets (20.0 vs 9.7 nmoles. $\mathrm{min}^{-1} \cdot \mathrm{mg}^{-1}$ protein; figure $2 \mathrm{E}$ ) and was actually found to respond to $\mathrm{NaCl}$ in a dose-dependent manner (figure 2F).

It was of interest to ascertain whether enzymes activities were correlated with changes in transcriptional activity of GABA metabolism genes. To achieve this objective, genes expression analysis was performed by qRT-PCR on total RNA isolated from entire WT plantlets treated for $24 \mathrm{~h}$ with increasing concentrations of $\mathrm{NaCl}$. Primers were designed in order to ensure specific amplification (see Methods section and Additional file 1 ). As shown in figure $2 G$, only the expression of 3 $G A D$ genes was detectable under our experimental conditions. GAD1 and GAD2, the two most expressed paralogs, showed contrasted expression changes in response to $\mathrm{NaCl}$ treatments. GAD1 expression, which is rootspecific [36], was shown to be gradually restricted as far as $\mathrm{NaCl}$ concentration increased. On the opposite, GAD2 expression, which is present in all parts of plant [37], was significantly enhanced when the salt level exceeded $100 \mathrm{mM}$ (figure 2G). GAD4 expression was much lower than those of the two other GAD isoforms but it was found to be significantly enhanced in $\mathrm{NaCl}-$ treated plantlets (figure 2G). GAD4 expression was indeed 5.3-fold higher in plantlets treated for $24 \mathrm{~h}$ with $150 \mathrm{mM} \mathrm{NaCl}$ than in control plantlets. In such plantlets, $P O P 2$ expression was 2.3 -fold higher than in control plantlets (figure $2 \mathrm{G}$ ) and was actually found to be the most expressed gene of the GABA metabolism suggesting a pivotal function in salt stress responses. Interestingly, SSADH expression was also enhanced at $100 \mathrm{mM}$ and $150 \mathrm{mM} \mathrm{NaCl}$ concentrations (figure 2G) indicating that whole GABA catabolism was transcriptionally up-regulated upon $\mathrm{NaCl}$ treatment. In parallel, expression of $\Delta^{1}$-pyrroline-5-carboxylate synthetase 1 (P5CS1), a well-known salt stress-induced gene involved in proline synthesis [38], was shown to be gradually induced, thus validating our experimental conditions (figure 2G).

\section{The GABA-T deficient mutant pop2-1 is ovsersensitive to} $\mathrm{NaCl}$

We tested the sensitivity to $\mathrm{NaCl}$ of the previously isolated GABA-T deficient pop 2-1 mutant [24] on agar medium and under more physiological conditions in soil. In both case, $\mathrm{NaCl}$ treatment induced severe phenotype in the mutant, even death on agar medium supplemented with $150 \mathrm{mM} \mathrm{NaCl}$, whereas no obvious difference occurred under control conditions between the mutant and its WT (figures $3 \mathrm{~A}$ and $3 \mathrm{~B}$ ). $\mathrm{NaCl}$ sensitivity was more obvious at the root level since no clear symptoms appeared in aerial part of plants for $\mathrm{NaCl}$ concentrations below $150 \mathrm{mM}$ (figure 3A). As a convenient way to decipher pop 2-1 oversensitivity to $\mathrm{NaCl}$, we compared primary root growths of pop2-1 mutant and WT on agar media supplemented with various salts or osmoticum. As shown in figure 4A, pop 2-1 root growth was found to be oversensitive to $\mathrm{NaCl}$. Unlike to WT, mutant root growth was indeed sharply reduced at 50 $\mathrm{mM} \mathrm{NaCl}$ and decreased linearly as $\mathrm{NaCl}$ concentration increased in the medium (figure $4 \mathrm{~A}$ ). $\mathrm{NaCl}$ concentration that induced $50 \%$ inhibition of root growth $\left(I_{50}\right)$ was close to $81 \mathrm{mM}$ for pop $2-1$ and $138 \mathrm{mM}$ for WT. Furthermore, this response was mainly due to $\mathrm{Na}^{+}$ because treatments with increasing concentration of $\mathrm{KCl}$ were less inhibitory for root growth of the mutant $\left(I_{50}=\right.$ $137 \mathrm{mM}$; figure 4B). The possibility of a pleiotropic sensitivity to toxic cations of pop 2-1 was ruled out since the mutant did not display special phenotype in response to $1 \mathrm{mM}$ spermidine and $100 \mu \mathrm{g} / \mathrm{ml}$ kanamycin (Additional file 2). In this context, it was of interest to verify whether pop 2-1 root growth was also affected by osmotic stress. For this purpose, we used osmotically active concentrations of mannitol and osmotically nonactive concentrations of the highly toxic $\mathrm{LiCl}$. Thus, pop 2-1 mutant did not appear to be oversensitive to mannitol (figure $4 \mathrm{C}$ ) while $\mathrm{LiCl}$ induced a strong inhibition of pop 2-1 root growth $\left(I_{50}=8.4 \mathrm{mM}\right.$ vs $15.2 \mathrm{mM}$ for WT; figure 4D). These observations indicate that pop 2-1 mutant is oversensitive to ionic stress, but not to osmotic stress.

Treatment of 10-day-old plantlets with $150 \mathrm{mM} \mathrm{NaCl}$ for 4 days induced a greater growth inhibition in pop 2-1 than in WT $(30 \%$ vs $13 \%$ of growth inhibition 

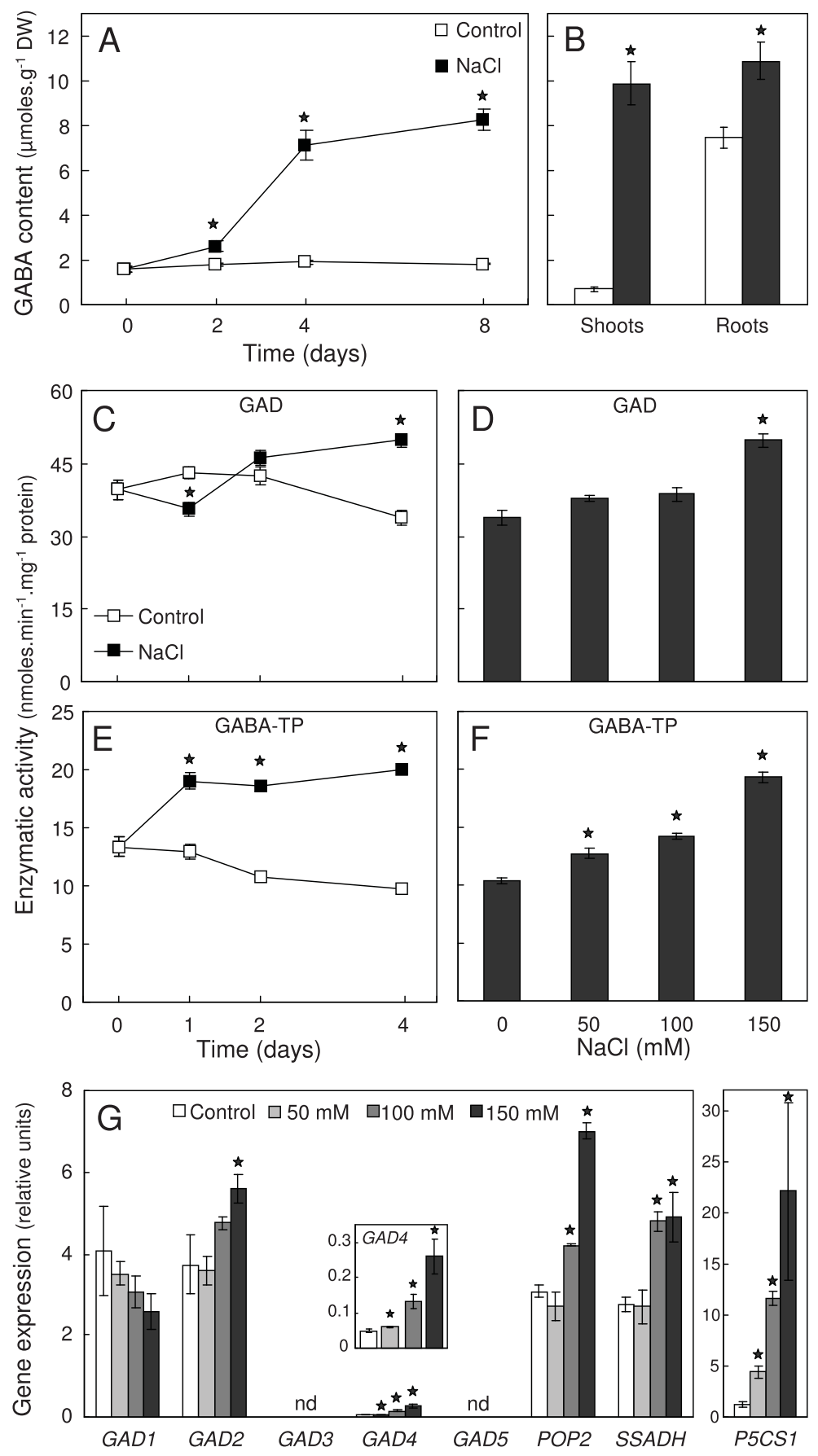

Figure 2 GABA metabolism regulation upon $\mathrm{NaCl}$ treatment. Ten-day-old plantlets of wild-type (WT, Ler accession) grown on agar medium were transferred to agar medium supplemented, or not (Control), with $\mathrm{NaCl}$. (A-B) Time-course and organ partitioning of GABA content during $\mathrm{NaCl}$ treatment. GABA content was determined either in whole plantlets treated with $150 \mathrm{mM} \mathrm{NaCl}$ over an 8-day-period (A) or in shoots and roots of plantlets after 4 days of treatment with $150 \mathrm{mM} \mathrm{NaCl}$ (B). Results are the mean \pm S.E. of 3 independent replicates. (C-F) Time-course and dose-response of GAD and GABA-TP activities upon NaCl. Glutamate decarboxylase activity (GAD, D-E) and GABA transaminase activity using pyruvate as GABA amino group acceptor (GABA-TP, F-G) were determined in entire plantlets either over a 4-day-period of treatment with 150 $\mathrm{mM} \mathrm{NaCl}(\mathrm{D}$ and $\mathrm{F}$ ) or after 4 days of treatment with increasing concentration of $\mathrm{NaCl}$ ( $E$ and $\mathrm{G}$ ). Results are the mean \pm S.E. of 4-10 independent replicates. (G) Dose-response of GABA metabolism genes to increasing concentration of $\mathrm{NaCl}$ after $24 \mathrm{~h}$ of treatment. Total RNA was isolated from whole plantlets and served to gene expression analysis of the five glutamate decarboxylase (GAD1-5), the GABA transaminase $(P O P 2)$, the succinate semialdehyde dehydrogenase (SSADH) and the well-known stress-induced $\triangle^{1}$-pyrroline-5-carboxylate synthetase 1 (P5CS1). Results are the mean \pm S.E. of 3 independent replicates. nd, not detected. Stars indicate a significant difference with control according to nonparametric Mann-Whitney $U$-test $(P<0.05)$ 


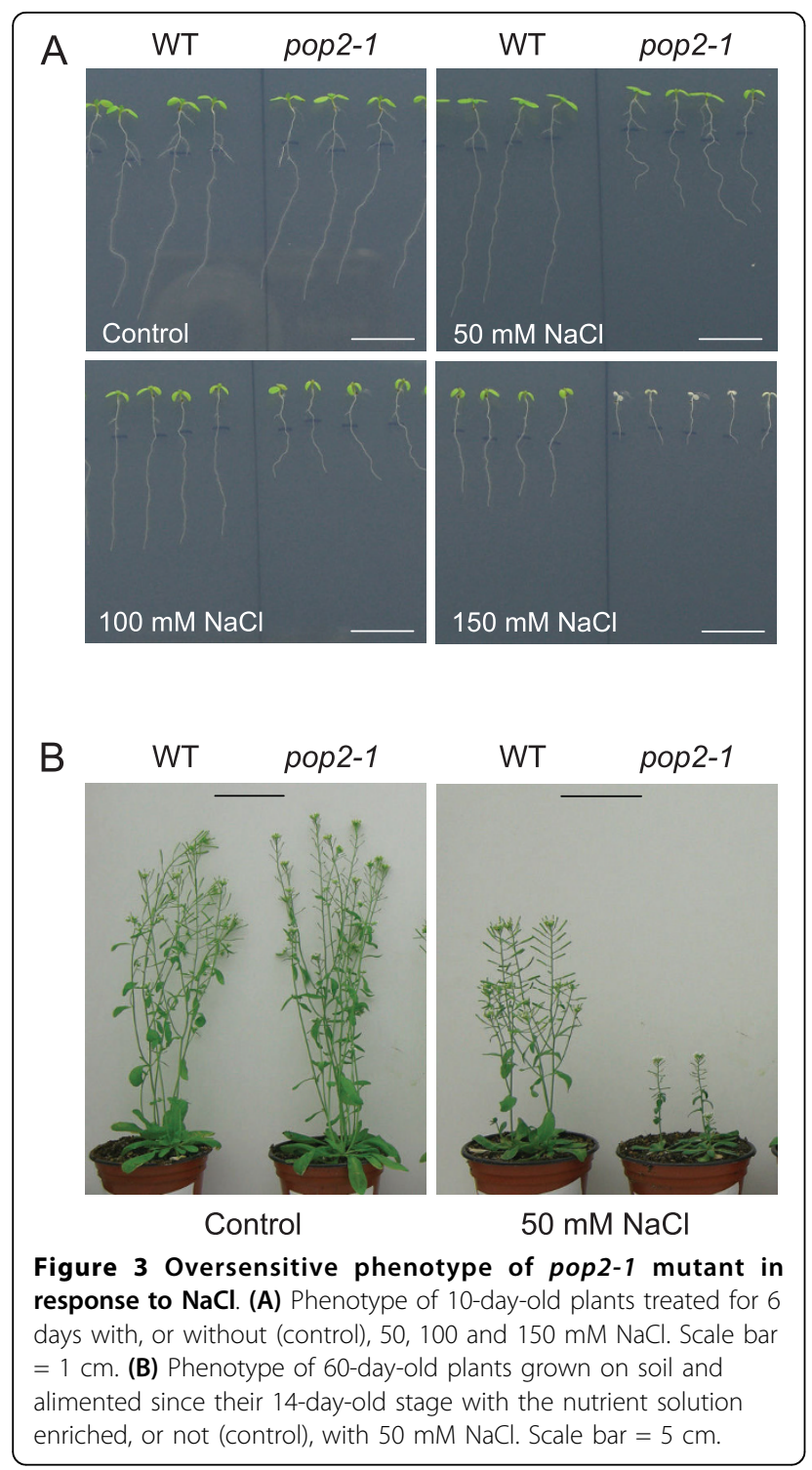

respectively; figures $5 \mathrm{~A}$ and $5 \mathrm{~B})$. The pop 2-1 growth restriction was not associated with overaccumulation of $\mathrm{Na}^{+}$(figure $5 \mathrm{C}$ ) or $\mathrm{Cl}^{-}$(figure 5D) in plant tissues that might lead to a higher internal ionic stress. However, $\mathrm{K}^{+}$ content was found to be significantly different between WT and pop2-1 mutant under both conditions (figure $5 \mathrm{E})$. Thus, whereas $\mathrm{K}^{+}$content was significantly greater in pop2-1 than in WT under control conditions (1.4 vs 1.2 mmoles. $\left.\mathrm{g}^{-1} \mathrm{DW}\right)$, pop2-1 exhibited a lesser $\mathrm{K}^{+}$content after $\mathrm{NaCl}$ treatment $\left(0.46\right.$ vs 0.59 mmoles.g ${ }^{-1} \mathrm{DW}$; figure $5 \mathrm{E}$ ). Nevertheless, the $\mathrm{K}^{+} / \mathrm{Na}^{+}$ratio of pop $2-1$ mutant after $\mathrm{NaCl}$ treatment was not found to be significantly different from that of WT $(0.24 \pm 0.009$ and 0.28 \pm 0.007 respectively, $P>0.05$, Mann-Whitney $U$-test; data not shown). To ascertain that the mutant was not impaired in $\mathrm{K}^{+}$uptake and transport, we germinated
WT and pop2-1 seedlings on agar nutrient medium with low $\mathrm{K}^{+}$content $(5 \mu \mathrm{M}, 50$ and $500 \mu \mathrm{M})$ and noted that pop2-1 grew as well as did the WT under low $\mathrm{K}^{+}$conditions (Additional file 3). Furthermore, the attempt to rescue pop2-1 phenotype on $150 \mathrm{mM} \mathrm{NaCl}$ medium by adding $20 \mathrm{mM} \mathrm{KCl}$ was unsuccessful (data not shown).

\section{Metabolic profiling of pop2-1 mutant reveals major}

\section{changes in roots upon $\mathrm{NaCl}$ treatment}

Metabolic disorders that might be induced by GABA-T activity impairment were investigated by profiling the major primary polar metabolites occurring in shoots and roots of WT and pop2-1 after 4 days of treatment with $150 \mathrm{mM} \mathrm{NaCl}$. A targeted analysis of GABA content in pop 2-1 mutant and its WT was first performed and showed that mutant constitutively overaccumulated GABA under control conditions compared with WT, about 18-fold more in shoots and 2.8-fold more in roots (figure 6A). Under $\mathrm{NaCl}$ conditions, GABA reached high levels in pop 2-1 mutant, especially in roots where the GABA content was close to $46 \mu$ moles.g ${ }^{-1} \mathrm{DW}$ (figure 6A). Principal component analysis was then performed in order to extract meaningful information from the whole dataset. Thus, we were able to separate all conditions on the two first components (figure 6B), which were found to explain more than $66 \%$ of the dataset variability. WT and pop $2-1$ shoots metabolic profiles were shown to be very close under control conditions and also, to a lesser extent, under $\mathrm{NaCl}$ conditions (figure $6 \mathrm{~B}$ ). In contrast, metabolic profile of pop 2-1 roots was clearly different from that of WT, especially after $\mathrm{NaCl}$ treatment as illustrated by the distance separating "Roots pop2-1 NaCl" cluster and "Roots WT NaCl" cluster (figure 6B). Among the 41 metabolites determined, 31 were shown to be present in a significantly different amount in pop 2-1 roots after $\mathrm{NaCl}$ treatment (figure $6 \mathrm{C})$. Interestingly, most of those that were more abundant in the mutant after $\mathrm{NaCl}$ treatment were amino acids while metabolites that were less abundant in the mutant were mostly carbohydrates (fructose, glucose, galactose, sucrose and trehalose; figure 6C). Surprisingly, succinate was shown to be significantly more abundant in roots of pop 2-1 after $\mathrm{NaCl}$ treatment (figure 6C) although this compound could partly result from GABA degradation (figure 1). Other TCA cycle intermediates (citrate, fumarate, malate), except 2-ketoglutarate which was more abundant in pop2-1 after $\mathrm{NaCl}$ treatment (figure $6 \mathrm{C}$ ), were not found to be present in a significantly different amount in roots of pop 2-1 and WT (absolute values in Additional file 4) suggesting that TCA cycle activity was not fundamentally compromised upon $\mathrm{NaCl}$ stress in mutant roots. In shoots, metabolic disorders induced by $\mathrm{NaCl}$ treatment seemed to be less severe since metabolite ratio between pop2-1 and WT were not so far different than under control conditions except for 


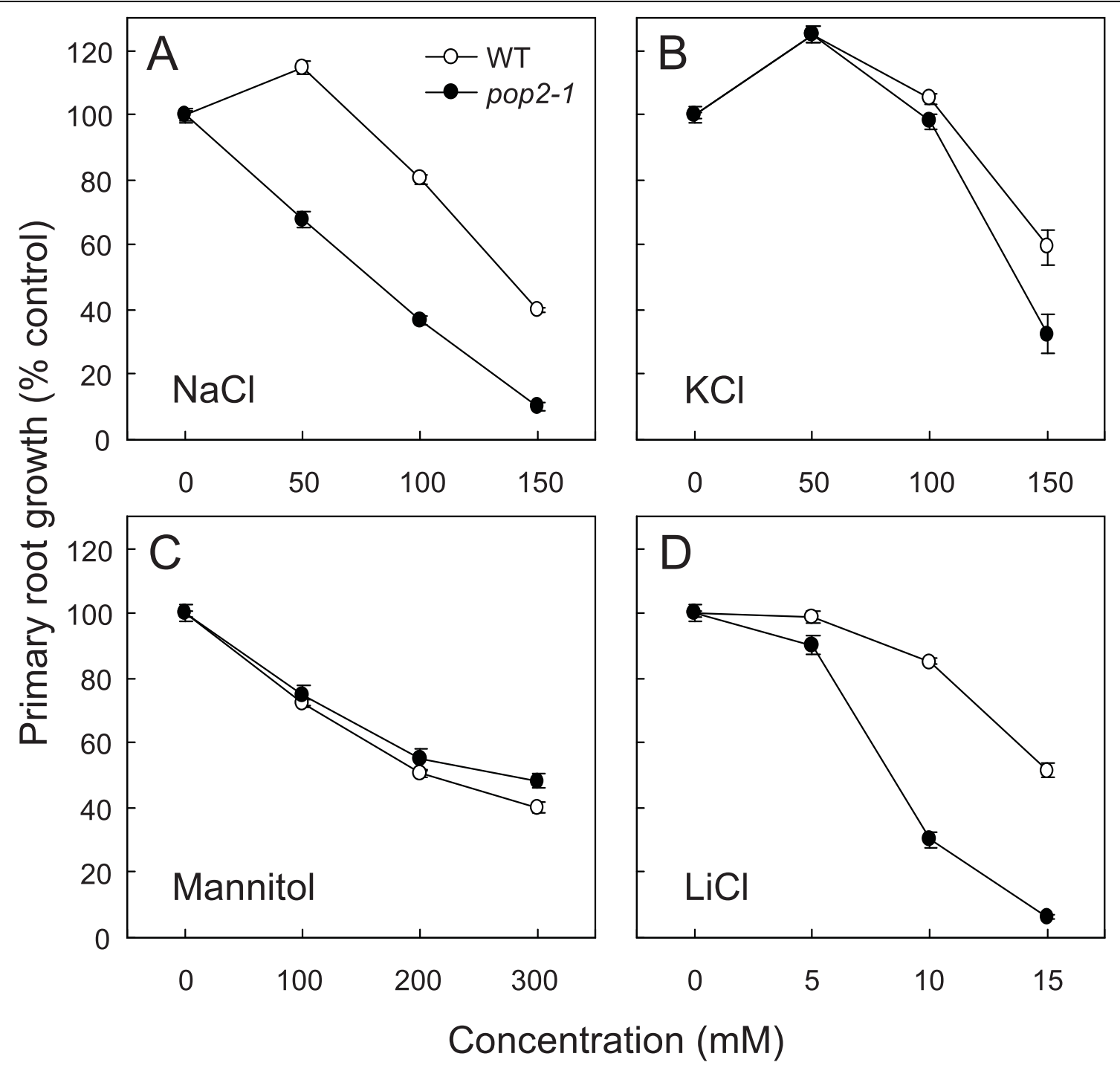

Figure 4 Oversensitivity of pop2-1 mutant to ionic stress. Four-day-old seedlings of WT and pop2-1 were transferred to agar medium supplemented with various concentrations of salts or osmoticum. After transfer, root apex was marked and primary root growth was recorded after 6 days. Primary root growth on agar medium supplemented with $\mathrm{NaCl}$ (A), $\mathrm{KCl}$ (B), Mannitol (C) and LiCl (D). Results are the mean \pm S.E. of measurements made on at least 16 plants distributed over three plates.

tryptophan and 2-ketoglutarate (Figure 6D). Unlike roots, shoots of pop 2-1 mutant were shown to accumulate more fructose, sucrose and glucose after $\mathrm{NaCl}$ treatment. Surprisingly, GABA did not belong to the most discriminant metabolites between WT and pop2-1 ( $\cos ^{2}$ $<0.75$; data not shown).

\section{$P O P 2$ expression pattern is reconfigured upon $\mathrm{NaCl}$} treatment

Ten-day-old homozygous transgenic plantlets harbouring $p P O P 2:: G U S$ construct (see Methods section) were subjected to $150 \mathrm{mM} \mathrm{NaCl}$ treatment for 2 days before GUS staining. Three independent lines were investigated and showed the same GUS staining patterns but with different intensity. Under control conditions, POP2 was mainly expressed in roots since no GUS staining was visible in shoots (figure 7A) whereas a strong staining was present in roots (figures 7B, D and 7F). Additionally, GUS staining was present along primary and secondary roots except in the division zone of root apex (figures 7B, D and 7F; for more details see Additional file 5). In salt-treated plants, GUS staining was visible in expanded cotyledons and leaves (figure 7A). This induction of POP2 may be a response to $\mathrm{Na}^{+}$accumulation in shoots and suggests that the enhanced $P O P 2$ expression measured by qRT-PCR (figure $2 \mathrm{C}$ ) was partly due to induction of the gene in shoots. GUS staining pattern of $\mathrm{NaCl}$-treated roots seemed to be more complex. GUS staining was indeed sharply reinforced in the terminal 


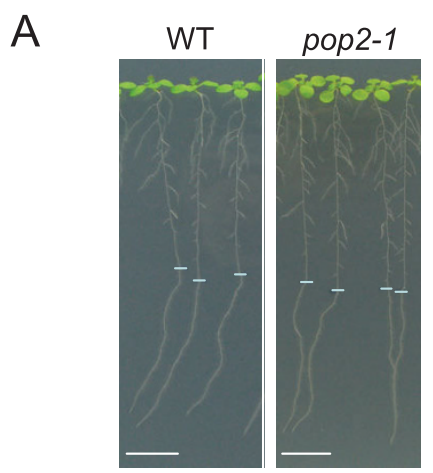

Control
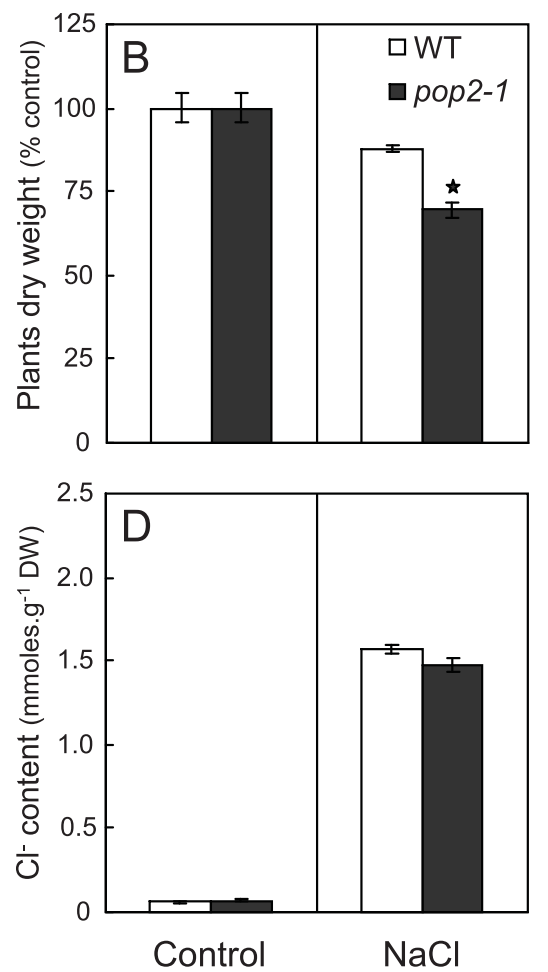

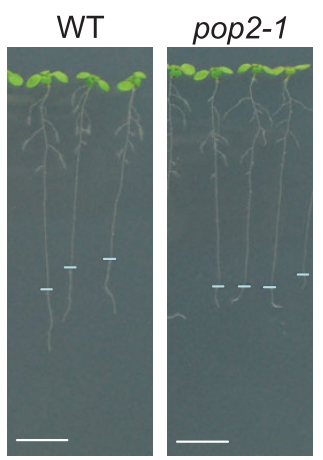

$150 \mathrm{mM} \mathrm{NaCl}$
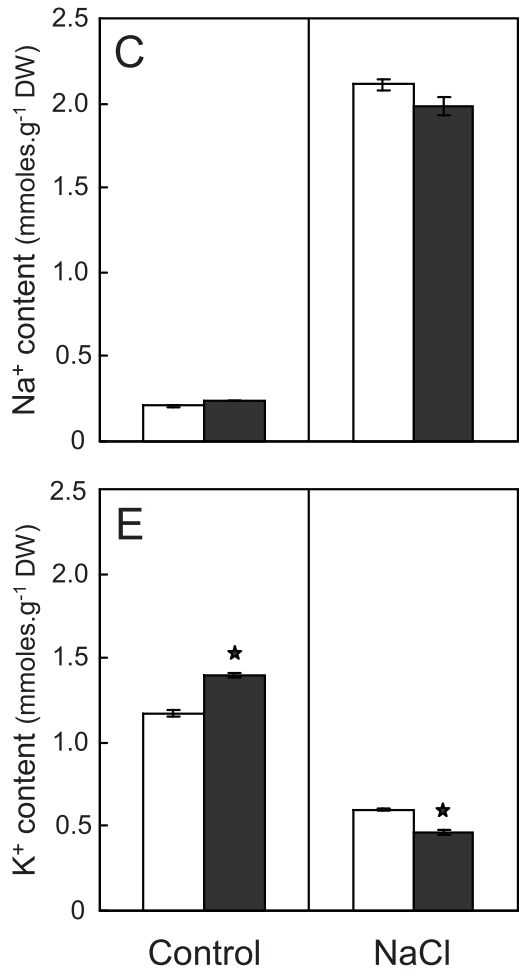

Figure 5 Phenotypic and physiological characterization of pop2-1 upon NaCl treatment. Ten-day-old plantlets of WT and pop2-1 mutant grown on agar medium were transferred for 4 days on agar medium supplemented, or not (Control), with 150 mM NaCl. For each condition, 15 entire plants were harvested for subsequent analysis. (A) Phenotype of plants at the end of NaCl treatment. Blue traits indicate primary root apex location at the onset of treatment. Scale bar $=1 \mathrm{~cm}$. (B) Plants dry weight after $\mathrm{NaCl}$ treatment. $\mathrm{Cl}^{-}$(C), $\mathrm{Na}^{+}(\mathbf{D})$ and $\mathrm{K}^{+}(\mathbf{E})$ content of plantlets after $\mathrm{NaCl}$ treatment. Results are the mean \pm S.E of 4 independent replicates. Stars indicate a significant difference with WT in the same condition according to non-parametric Mann-Whitney $U$-test $(P<0.05)$.

part of primary and secondary roots, especially in the central cylinder (figures 7C, E and 7G), while coloration disappeared in the central part of primary root (figures 7C and 7G).

\section{Discussion}

GABA levels control upon $\mathrm{NaCl}$ treatment involves transcriptional and biochemical events

The accumulation of GABA in response to $\mathrm{NaCl}$ exposure is a common feature of plants as reported in alfalfa
[39], tomato [40] and tobacco cells [41]. Until today, the molecular and biochemical events at the origin of this accumulation were misunderstood. Here, we showed in A. thaliana that GABA level changes under salt conditions were accompanied with variations of in vitro enzymes activities and transcription of GABA metabolism genes. Overall, GABA metabolism was found to be activated by $\mathrm{NaCl}$ treatment since almost all genes of this metabolism and both in vitro GAD and GABA-T activities were up-regulated (figure 2). These results 


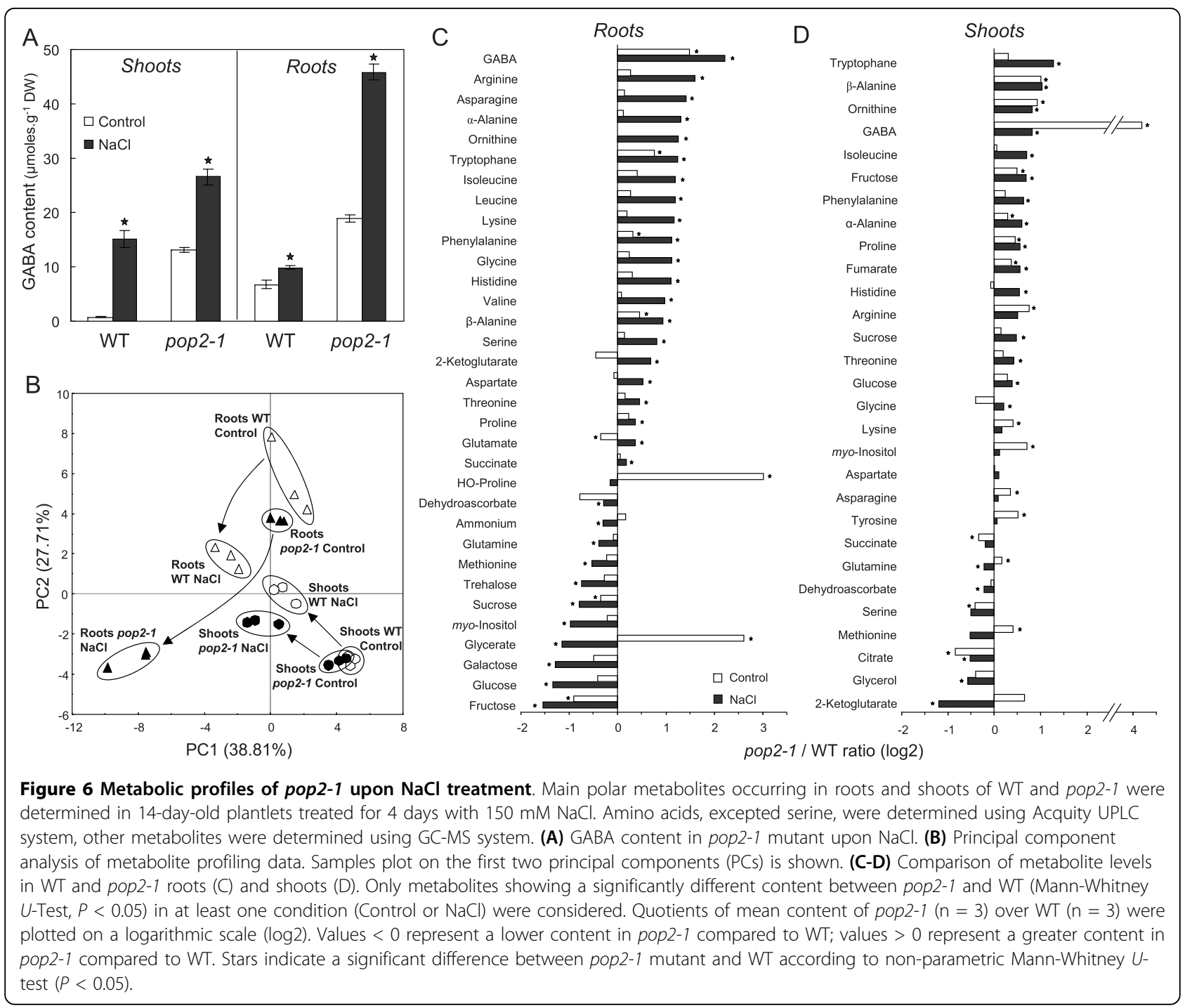

basically implicate GABA metabolism in salt responses of $A$. thaliana and also suggest that metabolic flux through this metabolism is of importance under stressful conditions. However, the determination of in vitro GAD and GABA-T activities failed to explain GABA level changes during the first days of $\mathrm{NaCl}$ treatment. Indeed, within the 2 first days, GAD activity was not found to be significantly enhanced in salt-treated plantlets, even was decreased after $24 \mathrm{~h}$ of $\mathrm{NaCl}$ exposure, while in the same time GABA level and GABA-T activity were found to be significantly increased. In this context, attention should be paid to the catalytic properties of plants GADs that are known to be tightly regulated at the post-translational level by $\mathrm{Ca}^{2+} / \mathrm{Calmodulin}$ complex $[28,29,42]$. Such post-translational regulation of GAD activity should be responsible for the rapid accumulation of GABA observed in response to cold and wounding $[17,43]$ and is likely to explain the discrepancy observed between in vitro GAD activity and GABA level evolutions given that $\mathrm{NaCl}$ treatments are known to trigger rapid elevation of cytosolic $\mathrm{Ca}^{2+}$ concentration [44]. Thus, GABA accumulation in the first time of $\mathrm{NaCl}$ exposure would mainly result from an activation of GAD activity by $\mathrm{Ca}^{2+}$ release in the cytosol; when stressful conditions are extended, GABA level control would implicate transcriptional regulation of GABA metabolism genes.

Transcriptional profiling of GABA metabolism genes demonstrated that almost all genes involved in GABA metabolism whose expression was detectable were upregulated in response to $\mathrm{NaCl}$ (figure 2G). Among the three $G A D$ genes whose expressions were detected, two paralogs were shown to be significantly up-regulated during $\mathrm{NaCl}$ treatment (GAD2 and GAD4; figure 2G). GAD2 expression has been shown to be ubiquitous in plant organs and to vary depending on nitrogen 


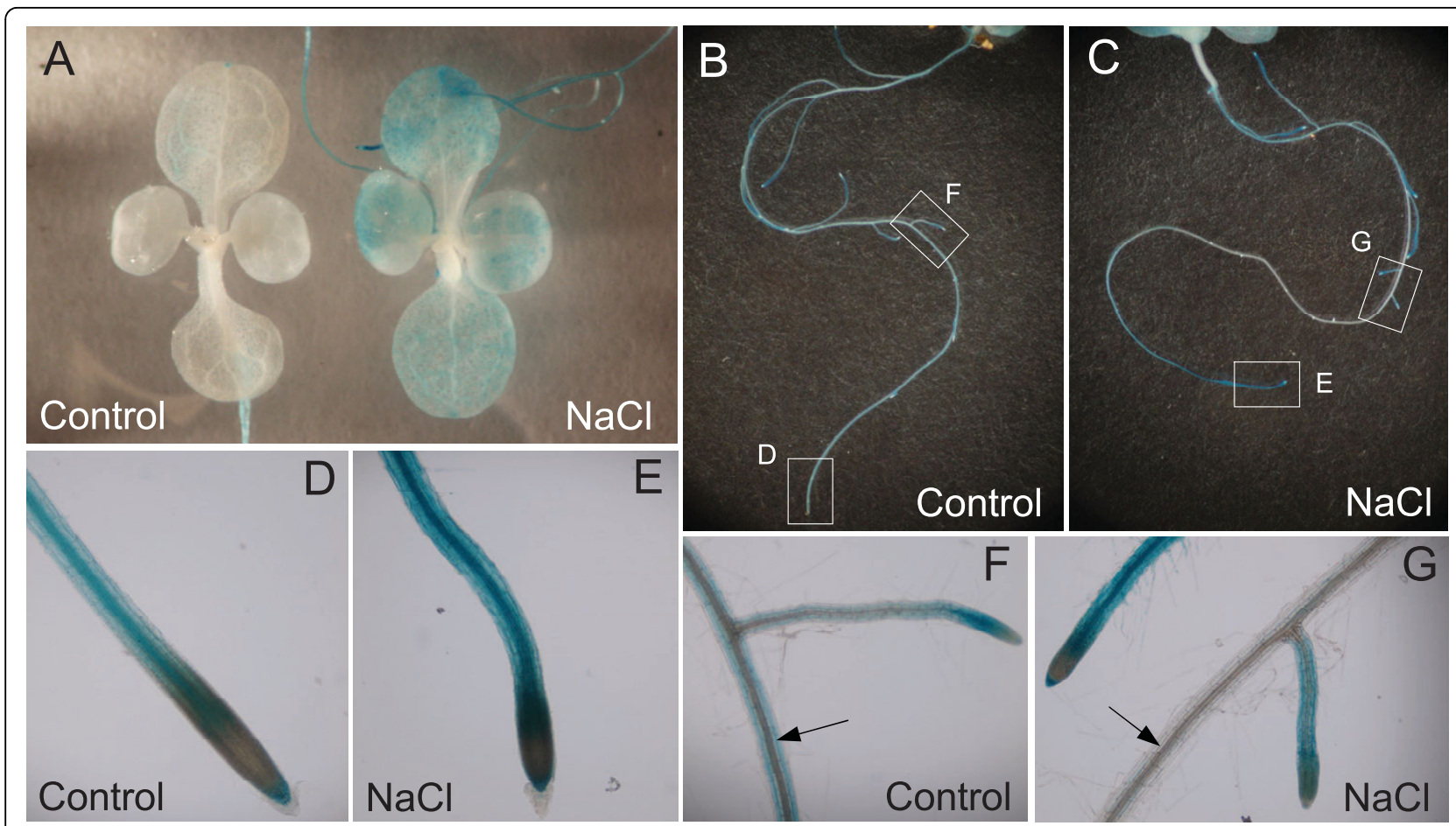

Figure 7 Histochemical analysis of POP2 promoter activity upon $\mathbf{N a C l}$ treatment. Ten-day-old plantlets of homozygous transgenic plants harbouring $P P O P 2:: G U S$ construct grown on agar medium were transferred for 2 days on agar medium supplemented, or not (Control), with 150 $\mathrm{mM} \mathrm{NaCl}$ before GUS staining. (A) GUS staining pattern in shoots of plantlets. (B-C) GUS staining pattern in roots of plantlets shown in A. (D-E) Focus on root apices visible in B and C. (F-G) Focus on areas under white boxes visible in B and C. Arrows point to primary root.

nutrition of plant suggesting involvement of this isoform in nitrogen metabolism [37]. Therefore, the increase of GAD2 expression at high $\mathrm{NaCl}$ concentration might be due to the necessity to adjust nitrogen metabolism under stressful conditions rather than to a specific response to $\mathrm{NaCl}$. Unlike to $G A D 2$, the putative GAD4 isoform seemed to be $\mathrm{NaCl}$-specific since we showed that its expression increased in a dose-dependent manner (figure 2G). This isoform appears to be not only $\mathrm{NaCl}$-responsive but is also involved in a variety of abiotic stresses since GAD4 was also shown to be induced in A. thaliana in response to hypoxia [35], cold treatment [45] and drought stress [46]. In addition, GAD4 was found to be overexpressed in the ABA-deficient $n c 3-2$ mutant in comparison to WT under drought stress indicating that ABA may be involved in the control of its expression [46]. Analysis of GAD4 expression pattern under stressful conditions may bring precious information on functions of the gene. In spite of the enhancement of two GAD expressions, GAD activity was shown to decrease after $24 \mathrm{~h}$ of treatment with $150 \mathrm{mM} \mathrm{NaCl}$. These results could be explained by (i) a time-delay between $G A D$ transcripts production and their translation, (ii) the decrease of GAD1 expression observed upon $\mathrm{NaCl}$ treatment (figure 2G). The two genes involved in GABA catabolism (i.e. POP2 and SSADH) were also found to be up-regulated at moderate and high $\mathrm{NaCl}$ concentrations (figure 2G). These data are consistent with a high importance of GABA catabolism upon $\mathrm{NaCl}$ treatment and also mean that GABA-T and SSADH steps would be coordinated, probably to prevent accumulation of the reactive succinic semialdehyde (SSA) since both enzymes are located into the mitochondrion in A. thaliana [26,34]. We found that POP2 was the most highly expressed gene involved in GABA metabolism after $24 \mathrm{~h}$ of treatment with $150 \mathrm{mM} \mathrm{NaCl}$ (figure 2G) and was induced both in shoots and some areas of roots upon $\mathrm{NaCl}$ (figure 7). Taking into account that POP2 coding sequence is thought to be present as a single copy in Arabidopsis genome [25,34], its prominent expression level suggests a pivotal function of GABA-T in GABA accumulation upon $\mathrm{NaCl}$ treatment. In parallel, a survey of public microarray databases reveals that POP2 is also responsive to osmotic stress $(x$ $4.5)$, senescence $(\times 4.05)$ and ABA treatment $(\times 2.47)$ [47] indicating an overall response of this step to environmental cues.

\section{The pop2-1 mutant is oversensitive to $\mathrm{NaCl}$}

To elucidate the contribution of the GABA-T to Arabidopsis $\mathrm{NaCl}$ responses, we performed a functional analysis of the Arabidopsis POP2 gene. The first step of number of gene functional analysis is to check 
phenotype of the corresponding loss-of-function mutant. Hence, we used the pop 2-1 mutant which was initially isolated and characterized for its quasi-sterility [24]. Recently, pop 2-1 mutant has been reported to be resistant to E-2-hexenal [30] and to accumulate a lesser amount of alanine in roots under hypoxia [35]. Here, we demonstrated that root growth of pop2-1 mutant was oversensitive to ionic stress since both $\mathrm{NaCl}$ and $\mathrm{LiCl}$ induced severe phenotype in mutant whereas mannitol did not (figure 4). This oversensitivity was also monitored at the plant biomass level at a later developmental stage (figure $5 \mathrm{~B}$ ). It is noteworthy that $P O P 2$-overexpessing plants neither showed improved salt tolerance (Additional file 6), even fed with $10 \mathrm{mM}$ GABA (Additional file 7), nor were found to exhibit special vegetative and reproductive phenotype (Additional files 6 and 8).

We can ask whether high GABA levels that occur in pop 2-1 mutant under control and even more under $\mathrm{NaCl}$ conditions (figure 6A) could not be toxic. Indeed, some data suggest that GABA overproduction is deleterious for plant development as shown in tobacco plants overexpressing a truncated GAD that lacks auto-inhibitory calmodulin binding site (GAD $\Delta C$ plants) [48]. However, since the GABA accumulation observed in these transgenic plants was also associated with a huge decrease of glutamate pool, authors did not conclude to a possible deleterious effect of GABA [48]. Arguments in favour of a non-toxic effect of high GABA levels are found in the literature as reported by Mirabella et al. [30] who associated high GABA levels to resistance to $E$-2-hexenal in $A$. thaliana either in wild-type plants fed with exogenous GABA or in the constitutively GABA accumulating pop $2 /$ her 1 mutants. Moreover, Ludewig et al. [31] also ruled out the hypothesis of a higher oxidative stress induced by high GABA level in pop 2 mutants since GABA accumulation was not shown to be associated with high reactive oxygen intermediates content. These findings are consistent with our observations indicating non-deleterious effects of $10 \mathrm{mM}$ exogenous GABA on WT plantlets both under control and $\mathrm{NaCl}$ conditions (data not shown).

Previous works showed that GABA seemed to have a tight link with $\mathrm{Na}^{+}$transport as shown in mammals where GABA is cotransported with $\mathrm{Na}^{+}$and $\mathrm{Cl}^{-}$[49] and in A. thaliana which was found to overaccumulate $\mathrm{Na}^{+}$when fed with GABA [50]. These observations led us to hypothesize that pop 2-1 oversensitivity to $\mathrm{NaCl}$ would be due to $\mathrm{Na}^{+}$and/or $\mathrm{Cl}^{-}$overaccumulation. However, determination of $\mathrm{Na}^{+}$and $\mathrm{Cl}^{-}$in plantlets subjected to $\mathrm{NaCl}$ treatment did not reveal any difference between pop 2-1 and its WT (figures 5C and 5D), thus invalidating our hypothesis. In contrast, $\mathrm{K}^{+}$was found to be present in a significantly lesser amount in mutant compared with its WT after $\mathrm{NaCl}$ treatment (figure 5E). This decrease may explain pop2-1 oversensitive phenotype in response to $\mathrm{NaCl}$ since a similar, but more severe, behaviour has been observed in the mutant of the Salt Overly Sensitive 1 locus [4]. Nevertheless, the pop 2-1 mutant was found to be able to grow on low $\mathrm{K}^{+}$ medium (Additional file 3), while sos 1 mutant did not, and the $\mathrm{K}^{+} / \mathrm{Na}^{+}$ratio in mutant was not shown to be different from that of WT (data not shown). All these data suggest that $\mathrm{K}^{+}$homeostasis in the mutant would not be so far disturbed. Finally, Armengaud and coworkers [51] showed that under low $\mathrm{K}^{+}$, Arabidopsis roots accumulated carbohydrates while organic acids content decreased. Such metabolites evolutions are not similar to those observed in pop 2-1 mutant (figure 6) indicating that the mutant did not experiment $\mathrm{K}^{+}$deficiency under $\mathrm{NaCl}$ treatment.

\section{GABA-T links $\mathrm{N}$ and $\mathrm{C}$ metabolisms in roots upon $\mathrm{NaCl}$ treatment}

Recently, a significant effort has been done to elucidate metabolic functions of GABA in higher plants [15]. Several evidences make sense with the idea that GABA metabolism in A. thaliana is highly active in roots, readily more than in shoots. First, we found that GABA was about 10-fold more abundant in roots than in shoots in WT plants under control conditions (figure 2B). This observation corroborates findings of Miyashita and Good [35] in hydroponically grown Arabidopsis plants. Besides, in accordance with previous results obtained by qRT-PCR [34], POP2 was shown to be mostly expressed in roots under control conditions (figure 7) suggesting that GABA degradation occurred at a high rate in this organ. Furthermore, GAD1, a root-specific GAD responsible for the maintenance of GABA level in roots, has been characterized in Arabidopsis [36] whereas no shoot-specific isoform is to date identified. Overall, these data lead us to assert that GABA metabolism would be of prime importance in roots.

The great inhibition of primary root growth triggered by $\mathrm{NaCl}$ treatment in pop2-1 mutant was accompanied with substantial changes in roots metabolite profiles of mutant in comparison to WT, and these changes appeared to be more important in roots than in shoots as revealed by PCA (figure 6B). These results argue in favour of a prominent metabolic function of GABA-T in roots under $\mathrm{NaCl}$ conditions. This assertion is also consistent with the POP2 expression pattern which was found to be tightly reconfigured in $\mathrm{NaCl}$-treated roots (figure 7). Metabolic changes in pop 2-1 mutant roots included accumulation of amino acids and decrease in carbohydrates (figure 6C) strongly suggesting a function for GABA-T, and in extenso for GABA metabolism, in the central $\mathrm{C} / \mathrm{N}$ metabolism. Several studies have reported the fluctuations of GABA content $[18,52,53]$ or 
the induction of GABA-TP encoding gene [54] along day or senescence also indicating a function for GABA metabolism in $\mathrm{C} / \mathrm{N}$ control. Furthermore, Fait et al. [15] found positive correlation of GAD and SSADH genes with several genes involved in central metabolism using the entire NASC0271 matrix. Overall, these findings give support to the fact that GABA plays a critical role in linking $\mathrm{N}$ and $\mathrm{C}$ metabolisms. Intriguingly, TCA cycle intermediates were not found to be present in a significant lesser amount in roots of pop 2-1 (figure 6C and Additional file 4 for absolute values) although GABA metabolism has been thought to play an anaplerotic function [14,17]. Such a function is supported by recent studies that investigated plants impaired in TCA cycle enzymes. In these experiments, GABA was often present at a differential level in enzyme impaired-plants indicating that GABA metabolism was regulated depending on TCA cycle activity and/or integrity. These results concerned plants compromised in enzymes involved in steps both up $[21,55,56]$ and down [57] to succinate production. The sharp decrease in carbohydrates content in pop 2-1 roots upon $\mathrm{NaCl}$ treatment may be due to the necessity to compensate GABA metabolism impairment by providing increased amount of pyruvate to TCA cycle through glycolysis, which has been shown to be functionally associated with the mitochondrion [58]. We attempted to rescue pop 2-1 phenotype by supplementing $\mathrm{NaCl}$ enriched medium with either $2 \%$ sucrose or with the combination of $10 \mathrm{mM}$ alanine and $10 \mathrm{mM}$ succinate, but attempts failed (data not shown) suggesting that metabolic impairment would not be the unique reason of pop2-1 phenotype.

In this context, we cannot exclude that a signaling effect of GABA would mediate pop2-1 oversensitivity. Indeed, GABA has been thought to act as a signaling factor in plants [17,59]. It has been shown to regulate nitrate uptake in Brassica napus [22] suggesting a function in regulation of nitrogen metabolism. Furthermore, GABA was found to down-regulate several 14-3-3 genes in a $\mathrm{Ca}^{2+}$-, ethylene- and ABA-dependent manner [23]. Given that 14-3-3 are regulatory proteins involved in development, metabolism and stress responses [60] and that GABA reached high levels upon $\mathrm{NaCl}$ treatment in pop 2-1 mutant (figure 6A), we can assume that these proteins would mediate metabolic changes recorded in the mutant.

\section{Conclusions}

Investigation of GABA metabolism regulation upon $\mathrm{NaCl}$ treatment at the metabolite, enzymatic activity and gene transcription levels brought new insights into its involvement in salt responses in A.thaliana. We provided evidences that GABA-T step was a key point of regulation of GABA metabolism under $\mathrm{NaCl}$ treatment.
Functional analysis of the GABA-T encoding gene $P O P 2$ revealed that it constituted a determinant of salt tolerance since the loss-of-function pop 2-1 mutant was shown to be oversensitive to ionic stress in spite of higher GABA levels in its tissues suggesting that GABA itself was not associated with tolerance. Promoter-gene strategy and metabolite profiling data demonstrated that GABA-T was of prime importance in roots upon $\mathrm{NaCl}$, especially linking $\mathrm{N}$ and $\mathrm{C}$ metabolisms.

\section{Methods}

\section{Plant material and growth conditions}

Seeds of Arabidopsis thaliana Ler accession (wild-type, WT) and pop 2-1 mutant (Ler background) [24] were provided by the Nottingham Arabidopsis Stock Centre. Seeds were surface-sterilized and sown on $1 \%(\mathrm{w} / \mathrm{v})$ sterile agar medium pH 5.7 (5 mM MES, Tris) in $12 \mathrm{~cm}$ square plates. The nutrient medium, based on Hoagland salts (half-strength for macronutrients), contained 2.5 $\mathrm{mM} \mathrm{Ca}\left(\mathrm{NO}_{3}\right)_{2}, 2.5 \mathrm{mM} \mathrm{KNO}_{3}, 1 \mathrm{mM} \mathrm{MgSO} 4,0.5 \mathrm{mM}$ $\mathrm{KH}_{2} \mathrm{PO}_{4}, 53.9 \mu \mathrm{M}$ FeNa-EDTA, $32.3 \mu \mathrm{M} \mathrm{H}_{3} \mathrm{BO}_{3}, 10.6$ $\mu \mathrm{M} \mathrm{MnSO}_{4}, 1.2 \mu \mathrm{M} \mathrm{ZnSO}_{4}, 1.2 \mu \mathrm{M} \mathrm{Na}_{2} \mathrm{MoO}_{4}, 0.8 \mu \mathrm{M}$ $\mathrm{CuSO}_{4}$ and $0.5 \mu \mathrm{M} \mathrm{Co}\left(\mathrm{NO}_{3}\right)_{2}$. After $2-3$ days at $4{ }^{\circ} \mathrm{C}$ in the dark to synchronize germination, plates were moved to a growth room at $22^{\circ} \mathrm{C}$ having a $12 \mathrm{~h}$-light period (light intensity of $100 \mu \mathrm{mol} . \mathrm{m}^{-2} \cdot \mathrm{s}^{-1}$ ) and $60 \%$ relative humidity. Plates were kept vertically and their tops were not wrapped to allow transpiration.

Treatments were carried out by supplementing nutrient agar medium with compound before autoclaving. Four-day-old seedlings (Boyes' stage 1.0) [61] or 10-dayold plantlets (Boyes' stage 1.02) were individually transferred to new agar plates. Age of plants was defined with respect to the end of cold treatment. Transfer was always performed $6 \mathrm{~h}$ after light onset in order to take into account circadian rhythms of plants.

\section{Primary root measurements}

To determine the effect of salts and osmoticum on primary root growth, mutant and wild-type seedlings were germinated on agar plates. Four days later, seedlings were transferred to salt- or osmoticum-supplemented plates and primary root apex was marked. Plates were photographed 6 days after transfer and root elongation was measured using the ImageJ software http://rsbweb. nih.gov/ij/. For each treatment, roots from 16 to 18 plants distributed over three plates were measured.

\section{lon content}

Ion content was determined in 14-day-old plantlets grown on agar medium that had been transferred for 4 days on agar plates supplemented with $150 \mathrm{mM} \mathrm{NaCl}$. Entire plantlets were harvested, abundantly rinsed in 4 successive baths of ultra-pure water, quickly blotted and snap-frozen in liquid nitrogen. Samples (15 plants) were freeze-dried and milled with $4 \mathrm{~mm}$ steel balls at $20 / \mathrm{s}$ 
frequency for $2 \mathrm{~min}$. Ions were extracted from $\sim 5 \mathrm{mg}$ of dry material in $1 \mathrm{ml}$ of $60^{\circ} \mathrm{C}$ ultra-pure water for $60 \mathrm{~min}$ under agitation. Following centrifugation at $20000 \mathrm{~g}$ for $10 \mathrm{~min}$, supernatants were recovered and diluted for ions analysis. $\mathrm{Na}^{+}$and $\mathrm{K}^{+}$were quantified using a Sherwood model 410 flame photometer (Sherwood Scientific, Cambridge, UK). $\mathrm{Cl}^{-}$was quantified by ionic chromatography on a Dionex DX120 (Dionex corporation, Sunnyvale, CA) with an AS9HC column and ion Pac AG9 HC precolumn. Ions were eluted by $\mathrm{Na}_{2} \mathrm{CO}_{3}$ buffer and detected by conductimetry.

\section{RNA isolation and quantitative RT-PCR analysis}

Total RNA was isolated from $30 \mathrm{mg}$ of fresh material using the SV Total RNA Isolation Kit (Promega Corporation, Madison, WI) following the manufacturer's protocol. Quantity, quality and integrity of each RNA sample was assessed spectrophotometrically with a Nanodrop ND 1000 and by visualising RNA on ethidium bromide stained agarose gel. Samples were treated by DNaseI using the TURBO DNA-free kit (Applied Biosystems Inc, Foster City, CA). Reverse transcription (RT) was performed in $10 \mu \mathrm{l}$ with an oligodT primer on $200 \mathrm{ng}$ total RNA using the Taqman $^{\odot}$ Reverse Transcription Reagents kit (Applied Biosystems Inc, Foster City, CA) according to the manufacturer's recommendations.

Primers were designed with Primer3Plus online software http://www.bioinformatics.nl/cgi-bin/primer3plus/ primer3plus.cgi with qPCR settings. Care was taken to ensure that primer pairs match all known splice variants. Reverse electronic-PCR http://www.ncbi.nlm.nih. gov/sutils/e-pcr/reverse.cgi was then performed for each selected primer pair to check for single bands and correct size amplification on Arabidopsis transcriptome and to determinate size amplification on Arabidopsis genome. Primer pairs matching these requirements were tested on dilution series of either cDNA $(1 / 10,1 / 40,1 /$ $160,1 / 640,1 / 2560$ ) or genomic DNA (5 ng, $0.5 \mathrm{ng}, 0.05$ ng, $0.005 \mathrm{ng}$ ) to generate a standard curve and evaluate their PCR efficiency, which ranged from $92 \%$ to $109 \%$ (list of primer pairs is visible in Additional file 1).

Quantitative PCR reactions were performed on 384wells plate in $10 \mu \mathrm{l}$, comprising $2 \mu \mathrm{l}$ of 40 -fold diluted $\mathrm{RT}$ reaction, $300 \mathrm{nM}$ final concentration of each primer and PowerSYBR Green PCR Master Mix (Applied Biosystems Inc, Foster City, CA). Plates were filled with PCR reagents using the epMotion 5070 automated pipetting system (Eppendorf, Hamburg, Germany). Corresponding RT minus controls were concurrently performed with each primer pair. PCR conditions were as follows: $95^{\circ} \mathrm{C}, 10 \mathrm{~min} ; 40 \times\left[95^{\circ} \mathrm{C}, 15 \mathrm{~s} ; 60^{\circ} \mathrm{C}, 1 \mathrm{~min}\right]$ and a final dissociation step to discriminate non-specific amplifications. All reactions were performed in triplicate with the 7900HT Fast Real-Time PCR System (Applied Biosystems Inc, Foster City, CA) and data were analyzed with the SDS 2.3 software provided by the manufacturer. PP2AA3 gene (At1g13320) [62] was used as internal standard. Relative gene expression was calculated using the $2^{-\triangle \mathrm{Ct}}$ equation, where $\Delta \mathrm{Ct}=\mathrm{Ct}_{\text {target gene }}$ $\mathrm{Ct}_{P P 2 A A 3}$.

\section{GABA-TP and GAD activities}

Ten- to fourteen-day-old plantlets were harvested, weighed and snap-frozen in liquid nitrogen. Samples were stored at $-80^{\circ} \mathrm{C}$ until processing. Proteins extraction and enzyme assays were performed according to Miyashita and Good [35] with some modifications.

For GABA-TP assay, protein extraction was performed in an extraction buffer containing $100 \mathrm{mM}$ Tris- $\mathrm{HCl}$ (pH 8.0), $5 \mathrm{mM}$ EDTA, $1.5 \mathrm{mM}$ dithiothreitol (DTT), $1 \%(\mathrm{v} / \mathrm{v})$ protease inhibitor cocktail (Sigma, \#P9599) and $10 \%(\mathrm{v} / \mathrm{v})$ glycerol. Four volumes of extraction buffer (v/ $\mathrm{w})$ and $1 \%(\mathrm{w} / \mathrm{w})$ polyvinylpyrrolidone (PVPP) were added to samples before homogenization with a $4 \mathrm{~mm}$ steel ball at 30/s frequency for $2 \mathrm{~min}$. Samples were then centrifuged at $20000 \mathrm{~g}$ for $20 \mathrm{~min}$ at $4^{\circ} \mathrm{C}$. Supernatant was used for the enzyme assay and protein quantification. Enzyme assay was performed with $15 \mu \mathrm{l}$ of protein extract $(\sim 30 \mu \mathrm{g}$ of protein $)$ in a reaction buffer containing $50 \mathrm{mM}$ Tris- $\mathrm{HCl}(\mathrm{pH} \mathrm{8.0)}, 1.5 \mathrm{mM}$ DTT, $0.75 \mathrm{mM}$ EDTA, $0.1 \mathrm{mM}$ pyridoxal-5-phosphate (PLP), $10 \%(\mathrm{v} / \mathrm{v})$ glycerol, $16 \mathrm{mM}$ GABA and $4 \mathrm{mM}$ of pyruvate in a final volume of $150 \mu \mathrm{l}$. Control assays were concurrently performed by replacing native enzyme extract by boiled enzyme extract in the assay. After incubation at $30^{\circ} \mathrm{C}$ for $60 \mathrm{~min}$, samples were incubated at $97^{\circ} \mathrm{C}$ for $7 \mathrm{~min}$ to stop the reaction. GABA-TP activity was evaluated by quantifying the amount of L-alanine produced by enzymatic assay using alanine dehydrogenase $(\mathrm{AlaDH}) . \mathrm{AlaDH}$ assay was performed with $40 \mu \mathrm{l}$ of the GABA-T assay in an assay mix containing $50 \mathrm{mM}$ sodium carbonate buffer ( $\mathrm{pH} 10.0$ ), $1 \mathrm{mM} \beta-\mathrm{NAD}^{+}$and 0.02 units of Bacillus subtilis AlaDH (Sigma, \#A7653) in a final volume of $200 \mu \mathrm{l}$. The increase of $\mathrm{OD}_{340 \mathrm{~nm}}$ was recorded using 96-well microplate reader. For each sample, a duplicate determination of alanine was done and $\mathrm{OD}_{340 \mathrm{~nm}}$ recorded for the corresponding control was subtracted. The amount of L-alanine was calculated according to external calibration curve of L-alanine.

For GAD assay, protein extraction was performed as described above in an extraction buffer containing 100 $\mathrm{mM}$ Tris- $\mathrm{HCl}$ (pH 7.5), $1 \mathrm{mM}$ EDTA, 1\% (v/v) protease inhibitor cocktail (Sigma, \# P9599) and 10\% (v/v) glycerol. Enzyme assay was performed with $15 \mu \mathrm{l}$ of protein extract $(\sim 30 \mu \mathrm{g}$ of protein) in a reaction buffer containing $150 \mathrm{mM}$ potassium phosphate ( $\mathrm{pH} 5.8$ ), $0.1 \mathrm{mM}$ PLP and $20 \mathrm{mM}$ L-glutamate in a final volume of 150 $\mu \mathrm{l}$. Control assays were conducted as previously described. After incubation at $30^{\circ} \mathrm{C}$ for $60 \mathrm{~min}$, samples were heated at $97^{\circ} \mathrm{C}$ for $7 \mathrm{~min}$ to stop the reaction. 
GAD activity was evaluated by quantifying the amount of GABA produced by enzymatic assay using GABase (Sigma). GABase assay was performed with $20 \mu \mathrm{l}$ of the GAD assay in an assay mix containing $75 \mathrm{mM}$ potassium pyrophosphate ( $\mathrm{pH}$ 8.6), $3.3 \mathrm{mM}$ 2-mercaptoethanol, $1.25 \mathrm{mM} \beta$-NADP ${ }^{+}, 5 \mathrm{mM}$ 2-ketoglutarate and 0.02 units of Pseudomonas fluorescens GABase (Sigma, \#G7509) in a final volume of $200 \mu \mathrm{l}$. The increase of $\mathrm{OD}_{340 \mathrm{~nm}}$ was recorded using 96-well microplate reader. For each sample a duplicate determination of GABA was done and $\mathrm{OD}_{340 \mathrm{~nm}}$ recorded for the corresponding control was subtracted. The amount of GABA was calculated according to external calibration curve of GABA.

Protein concentrations were determined by the Bradford method [63] with bovine serum albumin as standard.

\section{Metabolites determination}

Plant samples were harvested and immediately snap-frozen in liquid nitrogen. Samples were freeze-dried and then homogenized with $4 \mathrm{~mm}$ steel balls for $1 \mathrm{~min}$ at $25 /$ s frequency. Dry plant powder was suspended in 400 $\mu \mathrm{l}$ of methanol containing $200 \mu \mathrm{M}$ DL-3-aminobutyric acid (BABA) and $400 \mu \mathrm{M}$ ribitol as internal standards and agitated at $1500 \mathrm{rpm}$ for $15 \mathrm{~min}$. Subsequently, 200 $\mu \mathrm{l}$ of chloroform were added and samples were agitated for five additional minutes. Finally, $400 \mu \mathrm{l}$ of ultra-pure water were added, samples were then vigorously vortexed and centrifuged at $13000 \mathrm{~g}$ for $5 \mathrm{~min}$. Two aliquots of upper phase per samples were transferred to clean microtubes and dried in vacuo.

For amino acids analysis, dry residues were suspended in ultra-pure water and $10 \mu \mathrm{l}$ of the resulting extract were sampled for amino acids derivatization according to the AccQTag Ultra Derivitization Kit protocol (Waters Corporation, Milford, MA). Amino acids were analysed using an Acquity UPLC ${ }^{\circledast}$ system (Waters Corporation, Milford, MA) by injecting $1 \mu$ l of the derivatization mix onto an Acquity UPLC ${ }^{\oplus}$ BEH C18 $1.7 \mu \mathrm{m} 2.1 \times 100 \mathrm{~mm}$ column heated at $55^{\circ} \mathrm{C}$. Amino acids were eluted at 0.7 ml.min ${ }^{-1}$ flow with a mix of 10 -fold diluted AccQTag Ultra Eluent (A; Waters Corporation, Milford, MA) and acetonitrile (B) according to the following gradient: initial, 99.9\% A; $0.54 \mathrm{~min}, 99.9 \% \mathrm{~A} ; 6.50 \mathrm{~min}, 90.9 \% \mathrm{~A}$, curve 7 ; $8.50 \mathrm{~min}, 78.8 \% \mathrm{~A}$, curve $6 ; 8.90 \mathrm{~min}, 40.4 \% \mathrm{~A}$, curve 6; $9.50 \mathrm{~min}, 40.4 \% \mathrm{~A}$, curve 6; $9.60 \mathrm{~min}, 99.9 \% \mathrm{~A}$, curve $6 ; 10.10 \mathrm{~min}, 99.9 \%$ A. Derivatized amino acids were detected at $260 \mathrm{~nm}$ using a photo diode array detector. Amount of amino acids was expressed in $\mu$ moles per $g$ of dry weight of sample ( $\mu$ moles.g $\left.{ }^{-1} \mathrm{DW}\right)$ making reference to BABA signal, external calibration curve of amino acids and dry weight of samples.

For GC-MS analysis, dry residues were dissolved in 50 $\mu \mathrm{l}$ of freshly prepared methoxyamine hydrochloride solution in pyridine $(20 \mathrm{mg} / \mathrm{ml})$. Samples were agitated for $90 \mathrm{~min}$ at $30^{\circ} \mathrm{C}, 50 \mu \mathrm{l}$ of $N$-methyl- $N$-(trimethylsilyl) trifluoroacetamide (MSTFA; Sigma, \#394866) were then added and derivatization was conducted at $37^{\circ} \mathrm{C}$ for 30 min under agitation. After transfer to glass vials, samples were incubated at room temperature over-night before injection. GC-MS analysis was performed according to Roessner et al. [64]. GC-MS system consisted of a TriPlus autosampler, a Trace GC Ultra chromatograph and a Trace DSQII quadrupole mass spectrometer (Thermo Fischer Scientific Inc, Waltham, MA). Chromatograms were deconvoluted using the AMDIS software v2.65 http://chemdata.nist.gov/mass-spc/amdis/. Metabolites levels were expressed in relative units making reference to ribitol signal and dry weight of samples. Plasmids construction

All PCR amplifications were conducted with PfuLltra ${ }^{\text {тM }}$ II Fusion HS DNA polymerase (Stratagene Inc, La Jolla, CA). Amplified fragments were sequenced when introduced in either pDONR221 or pMDC32. All Gateway ${ }^{\odot}$ technology-related procedures were done according to the manufacturer's instructions.

POP2 promoter::GUS reporter construct was generated by amplification from Ler genomic DNA of a promoter fragment from $-1636 \mathrm{bp}$ up-stream to $9 \mathrm{bp}$ down-stream of the start codon of POP2 (At $3 g 22200)$ using the forward primer 5'-GGGGACAAGTTTGTACAAAAAAGCAGGCTGAGTTCACTAAATTCTCCTGAC-3' and the reverse primer 5'GGGGACCACTTTGTACAAGAAAGCTGGGTGCGATAACGACCATTTTCTCCTAC-3' (attB1 and $a t t \mathrm{~B} 2$ sites are respectively highlighted in bold). The resulting PCR fragment was cloned into pDONR221 vector by BP clonase (Invitrogen Corporation, Carlsbad, CA) reaction and subsequently transferred into pMDC162 binary vector [65] by LR clonase (Invitrogen Corporation, Carlsbad, CA) reaction. The resulting plasmid was designated pPOP2::GUS. For POP2 surexpression, POP2 ORF [GenBank:AY142571] carried by the Gateway clone G09523 from the Salk institute was transferred to pMDC32 binary vector [65] by LR clonase reaction. The resulting plasmid was designated $2 \times 35$ S::POP2. Binary vectors were introduced in Agrobacterium tumefaciens strain C58 pMP90 by electroporation.

\section{Plant transformation and selection of homozygous transgenic lines}

Transgenic plants were generated by floral dip [66] of Arabidopsis (Ler). pPOP2::GUS or $2 \times 35 \mathrm{~S}:: P O P 2$ constructs were used to transform $\mathrm{T}_{0}$ generation and $\mathrm{T}_{1}$ seeds were harvested in bulk, sown and screened on agar plates containing $15 \mathrm{mg} / \mathrm{L}$ hygromycin B. Hygromycin B-resistant plants were planted on soil, and the $\mathrm{T}_{2}$ seeds were harvested from individual $\mathrm{T}_{1}$ plants. The number of integrated T-DNA copies was indicated by 
segregation of the hygromycin B-resistance phenotype in $\mathrm{T}_{2}$ progeny. Transgenic lines showing a $\mathrm{Hyg}^{\mathrm{R}}: \mathrm{Hyg}^{\mathrm{S}}$ ratio of 3:1 were considered to be single-locus for the T-DNA insertion. $\mathrm{T}_{3}$ homozygous transgenic lines were used for the analysis of the promoter reporter gene histochemical localisation and physiological characterization.

\section{Histochemical staining of GUS activity}

For histochemical staining of GUS activity, plant material was washed twice in a solution containing $50 \mathrm{mM}$ potassium phosphate buffer $\mathrm{pH}$ 7.0, $0.5 \mathrm{mM}$ ferrocyanide, $0.5 \mathrm{mM}$ ferricyanide and $0.1 \%$ Triton X-100. Plant material was then vacuum infiltrated for 10 min with the same solution supplemented with $0.5 \mathrm{mg} / \mathrm{ml} \mathrm{X-Gluc}$ substrate before incubation at $37^{\circ} \mathrm{C}$. Care was taken to manipulate control- and treated-plants at the same time. After appropriate staining, chlorophyll was removed by washing leaves three times in $75 \%$ ethanol.

\section{Statistical analysis}

Non-parametric Mann-Whitney $U$-test, Duncan multirange test and principal component analysis (PCA) were performed using Statistica software v7.1 (StatSoft, Tulsa, OK, USA). Zero values from signal below detection limit were replaced by an arbitrary very small value (0.0001) for subsequent PCA. This concerned only HOProline and Trehalose levels under control conditions in shoots of both WT and pop2-1.

\section{Additional file 1: List of verified primer pairs used for qRT-PCR \\ analysis. Sequence accessions used for primers design are indicated. Click here for file \\ [http://www.biomedcentral.com/content/supplementary/1471-2229-10- 20-S1.PDF ] \\ Additional file 2: Response of pop2-1 mutant to various kinds of} toxic cations. Phenotype of 10-day-old plants treated for 6 days with, or without (Control), $1 \mathrm{mM}$ spermidine or $100 \mu \mathrm{g} / \mathrm{ml}$ kanamycin. Scale bar $=1 \mathrm{~cm}$. Experiment was performed three times with same results. Click here for file

[http://www.biomedcentral.com/content/supplementary/1471-2229-1020-S2.PDF

Additional file 3: Growth of pop2-1 mutant under low $\mathrm{K}^{+}$conditions Phenotype of 10-day-old plants grown on agar media containing 500, 50 or $5 \mu \mathrm{M}$ potassium. Potassium was deleted from nutrient solution by replacing $\mathrm{KNO}_{3}$ and $\mathrm{KH}_{2} \mathrm{PO}_{4}$ with $\mathrm{NH}_{4} \mathrm{NO}_{3}$ and $\mathrm{NH}_{4} \mathrm{H}_{2} \mathrm{PO}_{4}$ respectively, potassium concentration was set by addition of $\mathrm{KCl}$. Scale bar $=1 \mathrm{~cm}$. Experiment was performed twice with same results.

Click here for file

[http://www.biomedcentral.com/content/supplementary/1471-2229-1020-S3.PDF ]

\section{Additional file 4: UPLC- and GC-MS-based metabolite profiling}

dataset. Absolute values of metabolites levels are given in this excel

sheet.

Click here for file

[http://www.biomedcentral.com/content/supplementary/1471-2229-1020-S4.XLS ]

Additional file 5: pPOP2::GUS expression pattern in primary root apex. Histochemical analysis of $P O P 2$ promoter activity in primary root apex under control conditions.

Click here for file

[http://www.biomedcentral.com/content/supplementary/1471-2229-1020-S5.PDF ]
Additional file 6: Molecular and physiological characterization of POP2-overexpressing lines. (A) POP2 expression in 11-day-old plantlets WT and the three $2 \times 35$ S::POP2 lines. Stars indicate a significant difference with WT according to non-parametric Mann-Whitney $U$-test ( $P$ $<0.05$ ). (B) GABA content in 14 day-old plantlets of $W T$ and two POP2 overexpressing lines treated, or not (Control), with $150 \mathrm{mM} \mathrm{NaCl}$ for 4 days. Stars indicate a significant difference with WT according to nonparametric Mann-Whitney $U$-test $(P<0.05)$. (C) Root growth of WT and the three $2 \times 35$ S: :POP2 lines on agar medium supplemented, or not (Control), with $150 \mathrm{mM} \mathrm{NaCl}(\mathrm{NaCl})$ or $300 \mathrm{mM}$ mannitol (Mannitol). Different letter indicate a significant difference according to Duncan multi-range test $(P<0.01)$. Root growth was determined as reported for figure 3. (D) Phenotype of 60-day-old plants of WT, pop2-1 mutant and the three $2 \times 355:: P O P 2$ lines alimented since their 14-day-old stage with standard nutrient solution supplemented, or not (Control), with $50 \mathrm{mM}$ $\mathrm{NaCl}$. Scale bar $=5 \mathrm{~cm}$.

Click here for file

[http://www.biomedcentral.com/content/supplementary/1471-2229-1020-S6.PDF

Additional file 7: Primary root growth response of POP2-

overexpressing lines to $\mathrm{NaCl}$ and GABA. Primary root growth of POP2overexpressing lines on agar plates supplemented, or not (Control), with $150 \mathrm{mM} \mathrm{NaCl}(\mathrm{NaCl})$, or $150 \mathrm{mM} \mathrm{NaCl}+10 \mathrm{mM} \mathrm{GABA}(\mathrm{NaCl}+\mathrm{GABA})$. Experimental procedures are the same as reported in figure 4. Different letters indicate a significant difference with WT according to Duncan multi-range test $(P<0.01)$

Click here for file

[http://www.biomedcentral.com/content/supplementary/1471-2229-1020-S7.PDF

\section{Additional file 8: Phenotype of siliques of POP2-overexpressing} plants. Phenotype of siliques of 60-day-old plants alimented since their 14-day-old stage with standard nutrient solution supplemented, or not (Control), with $50 \mathrm{mM} \mathrm{NaCl}$. Scale bar $=0.5 \mathrm{~cm}$.

Click here for file

[http://www.biomedcentral.com/content/supplementary/1471-2229-1020-S8.PDF ]

\section{Acknowledgements}

Authors are grateful to Pr. François R. Larher for his helpful comments on manuscript and Dr. Raphaël Lugan for his help in GC-MS analysis. We thank Odile Henin for her excellent technical assistance with Dionex analysis. HR was supported by the Ministère de l'Enseignement Supérieur et de la Recherche. The "Agence Nationale de la Recherche" is acknowledged for its financial support (ANR-07-VULN-004, EVINCE) for the acquisition of the GCMS equipment.

\section{Author details}

${ }^{1}$ INRA - Agrocampus Ouest - Université de Rennes 1, UMR 118 Amélioration des Plantes et Biotechnologies Végétales, F-35653, Le Rheu cedex, France. ${ }^{2}$ CNRS - Université de Rennes 1, UMR 6553 EcoBio, Campus de Beaulieu, F35042 Rennes cedex, France. ${ }^{3}$ UMR 7208 BOREA, Station de Biologie Marine, Muséum National d'Histoire Naturelle, Place de la Croix, F-29900 Concarneau, France.

\section{Authors' contributions}

$H R, A E A$ and $C D$ conceived the study and designed experiments. HR, VA and MA performed the experiments. HR, AEA and CD carried out analysis and interpretation of experimental data including statistical analyses. HR, $A E A, D R, A B$ and $C D$ participated to the writing of the manuscript. All authors read and approved the final manuscript.

Received: 22 July 2009

Accepted: 1 February 2010 Published: 1 February 2010 


\section{References}

1. FAO Land and Plant Nutrition Management Service. http://www.fao.org/ ag/agl/agll/spush.

2. Munns R, Tester M: Mechanisms of Salinity Tolerance. Annual Review of Plant Biology 2008, 59(1):651-681.

3. Møller IS, Tester M: Salinity tolerance of Arabidopsis: a good model for cereals?. Trends in Plant Science 2007, 12(12):534-540.

4. Wu SJ, Ding L, Zhu JK: SOS1, a Genetic Locus Essential for Salt Tolerance and Potassium Acquisition. Plant Cell 1996, 8(4):617-627.

5. Apse MP, Aharon GS, Snedden WA, Blumwald E: Salt Tolerance Conferred by Overexpression of a Vacuolar $\mathrm{Na}^{+} / \mathrm{H}^{+}$Antiport in Arabidopsis. Science 1999, 285(5431):1256-1258

6. Rus A, Yokoi S, Sharkhuu A, Reddy M, Lee B-h, Matsumoto TK, Koiwa H, Zhu J-K, Bressan RA, Hasegawa PM: AtHKT1 is a salt tolerance determinant that controls $\mathrm{Na}^{+}$entry into plant roots. Proceedings of the National Academy of Sciences USA 2001, 98(24):14150-14155.

7. Berthomieu P, Conéjéro G, Nublat A, Brackenbury WJ, Lambert C, Savio C, Uozumi N, Oiki S, Yamada K, Cellier F, et al: Functional analysis of AtHKT1 in Arabidopsis shows that $\mathrm{Na}^{+}$recirculation by the phloem is crucial for salt tolerance. The EMBO Journal 2003, 22:2004-2014.

8. Sunarpi, Horie T, Motoda J, Kubo M, Yang H, Yoda K, Horie R, Chan W-Y, Leung $\mathrm{H}-\mathrm{Y}$, Hattori $\mathrm{K}$, et al: Enhanced salt tolerance mediated by AtHKT1 transporter-induced $\mathrm{Na}^{+}$unloading from xylem vessels to xylem parenchyma cells. The Plant Journal 2005, 44(6):928-938.

9. Tsugane K, Kobayashi K, Niwa Y, Ohba Y, Wada K, Kobayashi H: A Recessive Arabidopsis Mutant That Grows Photoautotrophically under Salt Stress Shows Enhanced Active Oxygen Detoxification. Plant Cell 1999, 11(7):1195-1206

10. Gao X, Ren Z, Zhao Y, Zhang H: Overexpression of SOD2 Increases Salt Tolerance of Arabidopsis. Plant Physiology 2003, 133(4):1873-1881.

11. Hayashi H, Alia, Mustardy L, Deshnium P, Ida M, Murata N: Transformation of Arabidopsis thaliana with the $\operatorname{cod} A$ gene for choline oxidase; accumulation of glycinebetaine and enhanced tolerance to salt and cold stress. The Plant Journal 1997, 12(1):133-142.

12. Szekely G, Abraham E, Cseplo A, Rigo G, Zsigmond L, Csiszar J, Ayaydin F, Strizhov N, Jasik J, Schmelzer E, et al: Duplicated P5CS genes of Arabidopsis play distinct roles in stress regulation and developmental control of proline biosynthesis. The Plant Journal 2008, 53(1):11-28.

13. Kinnersley AM, Turano FJ: $\gamma$-Aminobutyric Acid (GABA) and Plant Responses to Stress. Critical Reviews in Plant Sciences 2000, 19(6):479-509.

14. Bouché N, Fromm H: GABA in plants: just a metabolite?. Trends in Plant Science 2004, 9(3):110-115.

15. Fait A, Fromm H, Walter D, Galili G, Fernie AR: Highway or byway: the metabolic role of the GABA shunt in plants. Trends in Plant Science 2008, 13(1):14-19.

16. Steward FC, Thompson JF, Dent CE: $\gamma$-Aminobutyric acid: a constituent of the potato tuber?. Science 1949, 110:439-440.

17. Shelp BJ, Bown AW, McLean MD: Metabolism and functions of gammaaminobutyric acid. Trends in Plant Science 1999, 4(11):446-452.

18. Masclaux-Daubresse C, Valadier MH, Carrayol E, Reisdorf-Cren M, Hirel B: Diurnal changes in the expression of glutamate dehydrogenase and nitrate reductase are involved in the $\mathrm{C} / \mathrm{N}$ balance of tobacco source leaves. Plant, Cell \& Environment 2002, 25(11):1451-1462.

19. Carroll AD, Fox GG, Laurie S, Phillips R, Ratcliffe RG, Stewart GR: Ammonium Assimilation and the Role of $\gamma$-Aminobutyric Acid in $\mathrm{pH}$ Homeostasis in Carrot Cell Suspensions. Plant Physiology 1994, 106(2):513-520.

20. Crawford LA, Bown AW, Breitkreuz KE, Guinel FC: The Synthesis of $\gamma$ Aminobutyric Acid in Response to Treatments Reducing Cytosolic pH. Plant Physiology 1994, 104(3):865-871.

21. Studart-Guimarães C, Fait A, Nunes-Nesi A, Carrari F, Usadel B, Fernie AR: Reduced Expression of Succinyl-Coenzyme A Ligase Can Be Compensated for by Up-Regulation of the $\gamma$-Aminobutyrate Shunt in Illuminated Tomato Leaves. Plant Physiology 2007, 145(3):626-639.

22. Beuve N, Rispail N, Laine P, Cliquet J-B, Ourry A, Le Deunff E: Putative role of $\gamma$-aminobutyric acid (GABA) as a long-distance signal in up-regulation of nitrate uptake in Brassica napus L. Plant, Cell \& Environment 2004 27(8):1035-1046

23. Lancien M, Roberts MR: Regulation of Arabidopsis thaliana 14-3-3 gene expression by $\gamma$-aminobutyric acid. Plant, Cell \& Environment 2006, 29(7):1430-1436.
24. Palanivelu R, Brass L, Edlund AF, Preuss D: Pollen Tube Growth and Guidance Is Regulated by POP2, an Arabidopsis Gene that Controls GABA Levels. Cell 2003, 114(1):47-59.

25. van Cauwenberghe OR, Makhmoudova A, McLean MD, Clark SM, Shelp BJ: Plant pyruvate-dependent gamma-aminobutyrate transaminase: identification of an Arabidopsis cDNA and its expression in Escherichia coli. Canadian Journal of Botany 2002, 80:933-941.

26. Busch KB, Fromm H: Plant Succinic Semialdehyde Dehydrogenase. Cloning, Purification, Localization in Mitochondria, and Regulation by Adenine Nucleotides. Plant Physiology 1999, 121(2):589-598.

27. Breitkreuz KE, Allan WL, Van Cauwenberghe OR, Jakobs C, Talibi D, Andre B, Shelp BJ: A Novel $\gamma$-Hydroxybutyrate Dehydrogenase: identification and expression of an Arabidopsis cDNA and potential role under oxygen deficiency. Journal of Biological Chemistry 2003, 278(42):41552-41556.

28. Baum G, Chen Y, Arazi T, Takatsuji H, Fromm H: A plant glutamate decarboxylase containing a calmodulin binding domain. Cloning sequence, and functional analysis. Journal of Biological Chemistry 1993, 268(26):19610-19617.

29. Snedden WA, Arazi T, Fromm H, Shelp BJ: Calcium/Calmodulin Activation of Soybean Glutamate Decarboxylase. Plant Physiology 1995, 108(2):543-549.

30. Mirabella R, Rauwerda H, Struys EA, Jakobs C, Triantaphylides C, Haring MA, Schuurink RC: The Arabidopsis her1 mutant implicates GABA in E-2hexenal responsiveness. The Plant Journal 2008, 53(2):197-213.

31. Ludewig F, Haùser A, Fromm H, Beauclair L, Bouché N: Mutants of GABA Transaminase (POP2) Suppress the Severe Phenotype of succinic semialdehyde dehydrogenase (ssadh) Mutants in Arabidopsis. PLOS ONE 2008, 3(10):e3383.

32. Reddy VS, Ali GS, Reddy ASN: Genes Encoding Calmodulin-binding Proteins in the Arabidopsis Genome. Journal of Biological Chemistry 2002, 277(12):9840-9852

33. De Biase D, Barra D, Simmaco M, John R, Bossa F: Primary structure and tissue distribution of human 4-aminobutyrate aminotransferase. European Journal of Biochemistry 1995, 227:476-480.

34. Clark SM, Di Leo R, Dhanoa PK, Van Cauwenberghe OR, Mullen RT, Shelp BJ: Biochemical characterization, mitochondrial localization, expression, and potential functions for an Arabidopsis $\gamma$-aminobutyrate transaminase that utilizes both pyruvate and glyoxylate. J Exp Bot 2009, 60(6):1743-1757.

35. Miyashita Y, Good AG: Contribution of the GABA shunt to hypoxiainduced alanine accumulation in roots of Arabidopsis thaliana. Plant and Cell Physiology 2008, 49(1):92-102

36. Bouché N, Fait A, Zik M, Fromm H: The root-specific glutamate decarboxylase (GAD1) is essential for sustaining GABA levels in Arabidopsis. Plant Molecular Biology 2004, 55(3):315-325.

37. Turano FJ, Fang TK: Characterization of Two Glutamate Decarboxylase cDNA Clones from Arabidopsis. Plant Physiology 1998, 117(4):1411-1421.

38. Strizhov N, Abrahám E, Okrész L, Blickling S, Zilberstein A, Schell J, Koncz C, Szabados L: Differential expression of two P5CS genes controlling proline accumulation during salt-stress requires $A B A$ and is regulated by $A B A 1$, ABI1 and AXR2 in Arabidopsis. The Plant Journal 1997, 12(3):557-569.

39. Fougere F, Le Rudulier D, Streeter JG: Effects of Salt Stress on Amino Acid Organic Acid, and Carbohydrate Composition of Roots, Bacteroids, and Cytosol of Alfalfa (Medicago sativa L.). Plant Physiology 1991, 96(4):1228-1236.

40. Bolarín MC, Santa-Cruz A, Cayuela E, Pérez-Alfocea F: Short-term solute changes in leaves and roots of cultivated and wild tomato seedlings under salinity. Journal of Plant Physiology 1995, 147:463-468.

41. Binzel ML, Hasegawa PM, Rhodes D, Handa S, Handa AK, Bressan RA: Solute Accumulation in Tobacco Cells Adapted to NaCl. Plant Physiology 1987, 84(4):1408-1415

42. Ling V, Snedden WA, Shelp BJ, Assmann SM: Analysis of a Soluble Calmodulin Binding Protein from Fava Bean Roots: Identification of Glutamate Decarboxylase as a Calmodulin-Activated Enzyme. Plant Cell 1994, 6(8):1135-1143.

43. Bown AW, MacGregor KB, Shelp BJ: Gamma-aminobutyrate: defense against invertebrate pests?. Trends in Plant Science 2006, 11(9):424-427.

44. Knight $H$, Trewavas AJ, Knight MR: Calcium signalling in Arabidopsis thaliana responding to drought and salinity. The Plant Journal 1997, 12(5):1067-1067

45. Kaplan F, Kopka J, Sung DY, Zhao W, Popp M, Porat R, Guy CL: Transcript and metabolite profiling during cold acclimation of Arabidopsis reveals 
an intricate relationship of cold-regulated gene expression with modifications in metabolite content. The Plant Journal 2007, 50(6):967-981.

46. Urano K, Maruyama K, Ogata Y, Morishita Y, Takeda M, Sakurai N, Suzuki H, Saito K, Shibata D, Kobayashi M, et al: Characterization of the ABAregulated global responses to dehydration in Arabidopsis by metabolomics. The Plant Journal 2009, 57(6):1065-1078.

47. Zimmermann P, Hirsch-Hoffmann M, Hennig L, Gruissem W: GENEVESTIGATOR. Arabidopsis Microarray Database and Analysis Toolbox. Plant Physiology 2004, 136(1):2621-2632.

48. Baum G, Lev-Yadun S, Fridmann Y, Arazi T, Katsnelson H, Zik M, Fromm H: Calmodulin binding to glutamate decarboxylase is required for regulation of glutamate and GABA metabolism and normal development in plants. The EMBO Journal 1996, 15:2988-2996.

49. Kanner B, Bendahan A: Two pharmacologically distinct sodium- and chloride-coupled high-affinity $\gamma$-aminobutyric acid transporters are present in plasma membrane vesicles and reconstituted preparations from rat brain. Proceedings of the National Academy of Sciences USA 1990, 87:14150-14155.

50. Essah PA, Davenport R, Tester M: Sodium Influx and Accumulation in Arabidopsis. Plant Physiology 2003, 133(1):307-318.

51. Armengaud P, Sulpice R, Miller AJ, Stitt M, Amtmann A, Gibon Y: Multilevel Analysis of Primary Metabolism Provides New Insights into the Role of Potassium Nutrition for Glycolysis and Nitrogen Assimilation in Arabidopsis Roots. Plant Physiology 2009, 150(2):772-785.

52. Diaz C, Purdy S, Christ A, Morot-Gaudry J-F, Wingler A, MasclauxDaubresse C: Characterization of Markers to Determine the Extent and Variability of Leaf Senescence in Arabidopsis. A Metabolic Profiling Approach. Plant Physiology 2005, 138(2):898-908.

53. Allan WL, Shelp BJ: Fluctuations of $\gamma$-aminobutyrate, $\gamma$-hydroxybutyrate and related amino acids in Arabidopsis leaves as a function of the lightdark cycle, leaf age, and N stress. Canadian Journal of Botany 2006, 84:1339-1346.

54. Ansari MI, Lee R-H, Chen S-CG: A novel senescence-associated gene encoding $\gamma$-aminobutyric acid (GABA):pyruvate transaminase is upregulated during rice leaf senescence. Physiologia Plantarum 2005, 123(1):1-8.

55. Lemaitre T, Urbanczyk-Wochniak E, Flesch V, Bismuth E, Fernie AR, Hodges M: NAD-Dependent Isocitrate Dehydrogenase Mutants of Arabidopsis Suggest the Enzyme Is Not Limiting for Nitrogen Assimilation. Plant Physiology 2007, 144(3):1546-1558.

56. Araújo WL, Nunes-Nesi A, Trenkamp S, Bunik VI, Fernie AR: Inhibition of 2Oxoglutarate Dehydrogenase in Potato Tuber Suggests the Enzyme Is Limiting for Respiration and Confirms Its Importance in Nitrogen Assimilation. Plant Physiology 2008, 148(4):1782-1796.

57. Merwe van der MJ, Osorio S, Moritz T, Nunes-Nesi A, Fernie AR: Decreased Mitochondrial Activities of Malate Dehydrogenase and Fumarase in Tomato Lead to Altered Root Growth and Architecture via Diverse Mechanisms. Plant Physiology 2009, 149(2):653-669.

58. Giege P, Heazlewood JL, Roessner-Tunali U, Millar AH, Fernie AR, Leaver CJ, Sweetlove L: Enzymes of Glycolysis Are Functionally Associated with the Mitochondrion in Arabidopsis Cells. Plant Cell 2003, 15(9):2140-2151.

59. Bouché N, Lacombe B, Fromm H: GABA signaling: a conserved and ubiquitous mechanism. Trends in Cell Biology 2003, 13(12):607-610.

60. Roberts MR: 14-3-3 Proteins find new partners in plant cell signalling. Trends in Plant Science 2003, 8:218-223.

61. Boyes DC, Zayed AM, Ascenzi R, McCaskill AJ, Hoffman NE, Davis KR, Gorlach J: Growth Stage-Based Phenotypic Analysis of Arabidopsis: A Model for High Throughput Functional Genomics in Plants. Plant Cell 2001, 13(7):1499-1510.

62. Czechowski T, Stitt M, Altmann T, Udvardi MK, Scheible W-R: Genome-Wide Identification and Testing of Superior Reference Genes for Transcript Normalization in Arabidopsis. Plant Physiology 2005, 139(1):5-17.

63. Bradford MM: A rapid and sensitive method for the quantitation of microgram quantities of protein utilizing the principle of protein-dye binding. Analytical Biochemistry 1976, 72:248-254.

64. Roessner U, Wagner C, Kopka J, Trethewey RN, Willmitzer L: Simultaneous analysis of metabolites in potato tuber by gas chromatography-mass spectrometry. The Plant Journal 2000, 23(1):131-142.

65. Curtis MD, Grossniklaus U: A Gateway Cloning Vector Set for HighThroughput Functional Analysis of Genes in Planta. Plant Physiology 2003, 133(2):462-469.
66. Clough SJ, Bent AF: Floral dip: a simplified method for Agrobacteriummediated transformation of Arabidopsis thaliana. The Plant Journal 1998, 16(6):735-743.

doi:10.1186/1471-2229-10-20

Cite this article as: Renault et al.: The Arabidopsis pop2-1 mutant reveals the involvement of GABA transaminase in salt stress tolerance. $B M C$ Plant Biology 2010 10:20.

\section{Submit your next manuscript to BioMed Central and take full advantage of:}

- Convenient online submission

- Thorough peer review

- No space constraints or color figure charges

- Immediate publication on acceptance

- Inclusion in PubMed, CAS, Scopus and Google Scholar

- Research which is freely available for redistribution 